\title{
A communicative-tension model of change-induced collective voluntary turnover in IT
}

\author{
Rennie Naidoo \\ School of Information Technology, Department of Informatics, University of Pretoria, South Africa \\ E-mail address: rennie.naidoo@up.ac.za
}

\begin{abstract}
Losing talented IT employees, the most critical strategic resource in IT, during a major organizational change can be catastrophic to the overall performance of the IS organization. This paper develops a multi-layered communicative-tension model of change-induced collective voluntary turnover from a historical case study analysis. A major organizational change at a healthcare insurance firm's IT unit reveals the presence of three primary communicative tensions: alignment-autonomy, stability-change and expression-suppression. A group of employees, dissatisfied with the negative communicative practices employed by their managers in the midst of these communicative tensions, left the organization. A communicative-tension model of change-induced collective voluntary turnover complements and extends upon prior collective voluntary turnover research by accounting for the organizational change context and broader relational dynamics. This study offers practitioners important insights on how to manage communicative tensions during an IS organizational change to improve IT talent retention.
\end{abstract}

Keywords: case study; collective voluntary turnover; communicative tensions; employee retention; IS organizational change; relational dialectical theory 


\section{Introduction}

Google Now staff quit as tensions flares. ${ }^{1}$

Clinkle implodes as employees quit. ${ }^{2}$

At Zappos, some employees find offer to leave too good to refuse. ${ }^{3}$

- Recent headlines from Online Media

Despite the economic downturn, recent media stories indicate that multiple IT employees sometimes voluntarily leave their employer at the same time. The headlines cited above are evidence of changeinduced collective turnover in IT organizations. A group of disenchanted engineers from the Google Now team objected to a transfer from the Android to the Search department. The change created tension within the Now team and many team members left. Several Clinkle employees simultaneously left the payment rewards start-up. Tensions increased when their CEO withheld information about acquisition talks with Apple. About 14\% (210) of roughly 1,500 employees left Zappos, an independent subsidiary of Amazon.com, Inc., amid tensions about a change to a self-management structure called a holacracy. Employees who left were apparently dissatisfied about the new model which implied no traditional career path, no traditional bosses and no job titles. These examples illustrate both the prevalence of communicative tensions in IT organizational change-induced collective turnover and, in particular, the communication challenges leaders face in managing dissatisfied groups of employees. This is a serious problem for IT leaders, given the war for talent and the strategic benefits of retaining the knowledge, skills and abilities of talented employees (Ready et al., 2008; Nayar, 2010).

\footnotetext{
${ }^{1}$ https://www.androidpit.com/google-now-staff-quit-as-tensions-flare-for-ceo-sundar-pichai 2 http://techcrunch.com/2015/05/15/clunk/

3 http://www.wsj.com/articles/at-zappos-some-employees-find-offer-to-leave-too-good-to-refuse-1431047917? mod=rss_Technology
} 
The strategic information system literature acknowledges the value of IT employee talent in a range of strategizing processes (Peppard et al., 2014) from strategic planning (Earl, 1993; Baker, 1995), alignment (Henderson and Venkatraman, 1993; Reich and Benbasat, 2000), competitive advantage (Galliers, 1993; Ross et al, 1996), capabilities (Peppard and Ward, 2004), agility (Sambamurthy et al., 2003), implementation (Lederer and Sethi, 1988), digital business strategy (Bharadwaj, et al., 2013), knowledge management (Galliers and Newell, 2003), to outsourcing (Lacity and Hirschheim, 1993). While important contributions have been made about IT employee talent in strategizing (Peppard et al., 2014), some of the prevailing conceptions that emphasise capabilities and competencies informed by theories such as the resource-based view (Rivard et al., 2006) and social capital theory (Wasko and Faraj, 2005) offer a relatively sterile view of communicative practices and its constitutive role in strategizing. In contrast, recent conceptual advancements by IS strategy-as-practice researchers view successful strategizing as a social process that relies on the communicative competence of IT practitioners (Whittington, 2014; Marabelli and Galliers, 2016). Although this study focuses on specific communicative practices that can account for the loss of talented IT employees, it also extends the general understanding of IS strategizing by framing IT practitioners as part of a dynamic social process driven by communicative practices.

The loss of critical strategic resources - that is, multiple talented IT employees - during the same period as a major IS organizational change can be catastrophic to the overall performance of the IS organization, however, studies focusing on this phenomenon have been sparse (Baron et al., 2001). The majority of IT turnover research aims at explaining individual employee turnover decisions (Ghapanchi and Aurum, 2011; Joseph et al., 2007). In recent years, IT turnover researchers have suggested a shift from focusing solely on the experiences of individuals towards broader relational experiences (Joseph et al., 2007). Furthermore, common approaches used in prior research to study IT turnover have generally been divorced from the organizational context (Ghapanchi and Aurum, 2011; Joseph et al., 2007). Although press accounts, such as those noted above, have reported on a number of occasions that an organizational change somehow led to the collective turnover of IT employees, prior turnover research has been prone to omitting theorising about the role of the changing 
organizational context. Prior theorising has also omitted relational processes associated with the turnover of multiple employees during the context of a major organizational change. This study draws upon a wide range of literature from IS, human resource management, organizational change and communication studies, and comparing and theorising from empirical data to propose a communicative-tension model of change-induced collective turnover.

Change-induced collective turnover is defined as the turnover of multiple employees, during the same period they collectively experience a major organizational change, where the decision to leave the organization is based on shared communicative and negotiation processes. This paper argues that employees, who leave en masse during an organizational change, communicatively construct their relationships with other organizational actors at the interpersonal, group, intergroup, organizational and interdivisional levels - that is, a multi-level analytical approach should be applied to improve extant understanding of change-induced collective turnover. A dialectical perspective is used as an analytical tool in this paper to uncover the communicative tensions over opposing discourses at work during an organizational change and to explore how such tensions contributed to shaping a collective turnover pattern for a group of employees.

The study of change-induced collective turnover in IT is not easily examinable using conventional research approaches. Researchers, therefore, tend to rely on scandals, the popular media, and whistleblowers to peek into this cloaked world. The study performs a historical analysis of a collective turnover pattern that occurred during an organizational change at an IT unit of a multinational healthcare insurance firm headquartered in South Africa. This study is based on rare access to sensitive data from this organization during a crucial period. It investigates the events that culminated in a collective turnover of staff between 2000 and 2005, when many IT units responsible for ecommerce throughout the globe were facing increasing scrutiny and were being subjected to change.

The research objective is to understand how a group of employees' decision to leave the organization during a major organizational change to their IT unit involved shared communicative tensions. The 
key contribution of this paper is the proposal of the communicative-tension model of change-induced collective turnover, which improves upon extant understanding of communicative and negotiation processes present in change-induced collective turnover, beyond the individual and interpersonal level. In addition, this paper addresses two weaknesses in the extant literature: First, collective turnover in the context of an IS organizational change has been under-researched; Second, there have been calls for IT turnover research to move beyond the individual or psychological level of analysis to reflect on broader relational processes at work. This study has important practical applications as it is currently difficult for managers and practitioners to implement IS organizational change effectively in the absence of information on how to manage communicative tensions to mitigate the risk of collective turnover.

The remainder of the argument is structured as follows. The next section presents the conceptual foundation for the study by reviewing the literature of voluntary employee turnover and the use of a communicative tensions approach to understand organizational change. After a discussion of the historical method followed in the case study and the data collection process, the study continues with a multilevel communicative tension analysis to understand the unfolding of collective voluntary turnover during this period, followed by a discussion of the contribution of this research and its implication for both research and practice. The paper concludes with a summary of the contribution and acknowledgments of limitations as well as potential directions for future research.

\section{Conceptual Foundations}

This section reviews two streams of research that this study builds on and contributes to: the IT employee voluntary turnover and collective employee voluntary turnover literature, and contextual and relational communicative tensions in organizational change studies. 


\subsection{IT voluntary employee turnover: A critique of the single-level perspective}

Theory building efforts on IT employee turnover has been generally framed at a single-level of analysis. Ghapanchi and Aurum's (2011) systematic literature review confirms that most research did not consider the influence of multi-level interactions on IT employee turnover decisions. In their review of 72 studies from 1980 to 2008, they identified 5 antecedent categories of IT turnover: (1) individual factors; (2) job-related factors; (3) psychological factors; (4) organizational factors and (5) environmental factors. These categories consisted of 70 specific antecedents aimed at a single-level of analysis. Examples of specific antecedents ranged from job characteristics, demographic indicators, career orientation, and personality type to psychological factors such as overall job satisfaction, pay satisfaction, career satisfaction and organizational commitment. Tedium factors, such as emotional exhaustion and fatigue as well as career concerns such as remuneration and benefits, were also considered. Studies also examined organizational cultural factors such as socialization tactics, general discrimination, ethnic discrimination, negative organizational culture, politics and infighting as well as human resource practices such as distributive justice, training opportunities, and internal labour market strategy. Environmental factors, such as work-family conflict, perceived job alternativeness, technology advancements, and threat of professional obsolescence, were also investigated. These studies generally used surveys to examine point in time relationships between the abovementioned antecedents and the proxy dependent variable, turnover intentions (Ghapanchi and Aurum, 2011). Similarly, a meta-analysis of 33 studies by Joseph et al. (2007) found that a majority of the 43 antecedents to turnover intentions were at the individual level. For example, job satisfaction measures targeting individual employees were the most frequently studied antecedent of turnover intentions, while the second most frequently studied antecedent was organizational commitment.

Recent advancements in turnover research since these two major reviews have continued to emphasize single-level studies (See Table A1 in Appendix A for a summary of these studies). Some of these studies have looked at gender discrimination issues (Joseph et al. 2015), HR practices such as 
succession management capabilities (Tornack and Schumann, 2014), supervisor trust (Erturk, 2014), recognition and achievement (Cinni, 2014), work-life imbalance (Goswami 2014; Zhao and Rashid, 2010), work exhaustion and stress related issues (Armstrong et al., 2015; Maier, et al., 2015; Shih et al., 2013; Calisir et al., 2011; Paige et al., 2008), IT career mobility (Joseph et al., 2012), discrepancy in career anchors (Chang et al., 2012; Jiang, 2011), organizational commitment and professional commitment (Cho and Huang, 2012), job utility (Dinger et al., 2012), personality traits of IT personnel (Eckhardt et al., 2014) and even user attitudes towards new technology (Maier et al., 2013; Ragu-Nathan et al., 2008). Even though some of the antecedents within the individual, job-related, psychological, organizational and environmental categories can enrich a multilevel analysis (group, unit, and organizational levels) of turnover (Holtom et al. 2008; Bartunek et al. 2008), they are generally treated as inputs to individual decisions.

The observation that models generally have a single-level emphasis may be related to the use of referent organizational behaviour theories that predict individual turnover. A majority of the models tend to incorporate concepts, only partially, from the inducements-contributions balance and equilibrium theory, social exchange theory, organizational role theory, human capital theory, search theory, met expectations theory, equity theory, range of affect theory, to name a few (Readers can refer to Joseph et al. (2007) for more in-depth overviews of these and other theories). Neither Joseph et al. (2007) nor Ghapanchi and Aurum (2011) identified a single study that conceptualises voluntary turnover research as a multi-level phenomenon. Although more than 100 articles have been published on turnover at the group, unit, and organizational levels in the HR literature (Hausknecht and Trevor, 2011), no specific IT employee turnover study has considered how the relational and specifically the group nature of the IT working environment may be influencing turnover decisions (See Table A2 in Appendix A for a summary of opportunities for future IT turnover studies).

One notable study by Lacity et al. (2008) did suggest that social pressure external to the employee, such as subjective norms - like family and peer pressure - should be considered in future studies. Another exception in IT research is a case study by Adam and Urquhart (2009). They drew from the 
notion of cultural capital to offer a multi-level analysis of IT capacity building challenges. However, they only touch on the high turnover problem. The problem with the term high turnover is that it is a simplistic way to convey that a certain amount of employees left an organization. Some HR researchers have been arguing that the collective turnover phenomenon is conceptually and empirically different from individual turnover. These advancements are discussed next.

\subsection{Toward a multi-level process model of collective turnover}

The notion of collective turnover is not new. Researchers commonly refer to 'organizational turnover', 'attrition rates', 'turnover rates' or 'heightened turnover' to distinguish from individual turnover - an individual's decision to stay or leave. More formally, collective turnover has been viewed "by the aggregate levels of employee departures that occur within groups, work units, or organizations" (Hausknecht and Trevor, 2011, p. 353); as the quantity and quality of "depletion of employee knowledge, skills, abilities and other characteristics" from organizational units (Nyberg et al., 2013, p. 109); as "those instances in organizational life when two or more people choose to leave their organization in close temporal proximity based on shared social processes" (Bartunek et al., 2008, p. 5); and even as turnover contagion - that is, when co-workers searching for job alternatives or quitting, spreads through a process of social contagion, influencing other employees' turnover behaviour (Felps et al., 2009).

As with individual turnover, the great majority of prior studies of collective turnover have also been concerned with variance models that address the relationships between discrete antecedent and dependent variables. Hausknecht and Trevor's (2011) extensive review groups the antecedents of collective turnover into three major categories: (1) HR systems and practices; (2) collective attitudes and perceptions; and (3) collective characteristics. The first major category of antecedents involves HR systems and practices such as selective staffing, incentive pay, extensive training, voice mechanisms that can enhance employee skills, motivation, and empowerment, consequently leading to higher retention. The second major category of antecedents involves collective-level attitudes and 
perceptions such as the collective views of management/leadership quality, climate/culture, cohesiveness/teamwork, and a host of attitudes that are known predictors of individual-level turnover such as satisfaction, commitment, fairness, and trust. The third major category of antecedents is organized into three subcategories: (1) member characteristics, (2) establishment characteristics, and (3) labour market characteristics. Member characteristics include factors such as diversity, size, union status, and member behaviours (absenteeism, organizational citizenship behaviours). Establishment characteristics include factors such as size (e.g., square footage), quality and age. Labour market characteristics include factors such as unemployment rates, employment alternatives, and labour costs (Readers can refer to Hausknecht and Trevor (2011) for more in-depth overviews of these factors).

A more recent review and analysis of 82 studies by Heavey et al. (2013) identified 6 categories of collective turnover antecedents: (1) strategic human resource management (HRM) inducements and investments, (2) HRM expectation-enhancing practices, (3) shared attitudes toward the job and organization, (4) quality of workgroup and supervisory relations, (5) job-alternative signals, and (6) job-embeddedness signals. This study found 2 categories, human resource management inducements/investments and job embeddedness signals, to be most strongly related to collective turnover. For instance, the turnover contagion model employs the social comparison process to explain why employees who are not embedded in their jobs are more likely to mimic co-workers' job behaviours, such as leaving, that can spread throughout a work group (Felps et al., 2009). Despite these advances, researchers studying collective turnover have been criticised over the years for generalizing individual-level theories and findings to a multi-level phenomenon (Krackhardt and Porter, 1986; Hausknecht and Trevor, 2011). Many of these theories also tend to neglect the nature of interactions among organizational unit members, the context within which they interact, and how these lower level interactions contribute to the emergence of turnover (Nyberg et al., 2013).

Scholars have begun adopting process studies of collective turnover to overcome some of the inherent weaknesses in relying too much on variance studies (Bartunek et al., 2008). Instead of focusing on the relationships between discrete predictor variables measured at discrete points in time to predict a 
certain outcome variable, they employ process studies to explain how a sequence of events unfolds over time to culminate into an outcome (van de Ven, 2007; van de Ven and Huber, 1990; van de Ven and Poole, 1995). Process studies also provide stories to explain the underlying generative mechanisms that give rise to this process (Langley and Montréal, 2007). However, the notion that a process can culminate into individual turnover is not new. Advancements such as the unfolding turnover model found that individual turnover is triggered by some type of shock or disruptive events (Holtom et al., 2005)

Nevertheless, much of the collective turnover literature and process theories are still predicated on and constrained by a single-level rationale. While these theories have their merit, a multi-level theory of collective turnover has been notably absent in the IT and HR literature (Hausknecht and Trevor 2011; Holtom et al. 2008; Bartunek et al. 2008). The need for more novel multi-level process theories which explain collective turnover was partly addressed by Bartunek et al. (2008). Based on a longitudinal case study approach, they proposed a novel escalating interaction process model of collective turnover. Their relational model shows how shared sensemaking and emotional contagion culminates into negative group experiences. They argue that group members, whose complaints go unaddressed, form increasingly negative shared perceptions and feelings that are only resolvable by leaving the organization. While their model carefully considers the importance of relational processes and voice, Bartunek et al. (2008) acknowledge that further conceptual development is needed to enrich our understanding of collective turnover, especially involving larger groups and intergroup relations. Holtom et al. (2008) also recommend the investigation of disruptive and destabilising events, such as organizational change (See Table A3 in Appendix A for a summary of multi-level collective studies).

\subsection{A relational dialectical perspective of change-induced collective turnover}

Although there are many studies of organizational change, few identify the relational processes at the organizational, group or interpersonal level that are salient to the employee's decision to leave (Baron et al., 2001; Rafferty and Griffin, 2006). Social constructivist (Berger and Luckmann, 1967) and 
structuration perspectives (Giddens, 1984) contend that social interaction is crucial in social change. The important role of context and social processes in organizational change has been noted in the fields of strategic management (Pettigrew et al., 2001; van de Ven and Huber, 1990; van de Ven and Poole, 1995) and IT (Myers and Klein, 1999; Walsham and Waema, 1994). More specifically, the importance of social processes where dialectics are central to social interaction, have provided useful insights in strategic organizational change (Benson, 1977; de Rond and Bouchikhi, 2004; Mason, 1969; Jay, 2013), corporate social responsibility (Dhanesh, 2015), change management (Ford and Ford, 1994; Kovoor-Misra, 2009), and IT studies (Cho et al., 2007; Robey and Holmstrom, 2001; Sabherwal and Newman, 2003).

Berger claims that "the subjective reality of the social world hangs on the thin thread of conversation" (1967, p. 26). The performative (i.e. reality producing) role of conversation and its dialectical nature, in particular, has received special attention in strategic organizational change (Hardy, Lawrence, and Grant, 2005; Schweiger and Denisi, 1991), change management (Ford and Ford, 2008; Ford et al., 2002) and more recently as 'grumbling' in information systems (Laumer et al., 2014). While both general turnover (Holtom et al., 2005; Scott et al., 1999) and IT turnover studies (Allen et al., 2006; Hall et al., 2008) have noted the importance of communication issues, they focus on communication inadequacies of supervisors and technology mediums, and soften the duality and contradictions involved in communication activities. A few researchers in the communication field have drawn on a relational dialectics approach to gain insights into these kinds of tensions (Erbert et al., 2005; Gibbs, 2009; Lee and Roth, 2007; Tracy, 2004). This theoretical perspective that accounts for contradictory processes in social interaction provides a strong complement to existing research on employee level and collective level turnover.

Relational dialectics theory (RDT), developed by Baxter and her colleagues (Baxter and Braithwaite, 2009; Baxter and Montgomery, 1996), by drawing from the work of Russian scholar Mikhail Bakhtin, can be used to develop theoretical insights about communicative tensions at multiple levels in an organization. This study assumes that sensitizing concepts in relational dialectics can lead to an 
enhanced understanding of collective turnover. Bakhtin (in Holquist, 2002) argues that communicative tensions play a central role in social interaction. Bakhtin views communicative tensions as the interplay between incompatible or oppositional forces: centripetal forces (emotional forces that create unity) and centrifugal forces (emotional forces that create division). These emotions are not viewed simply as cognitive and discrete internal states, but also as relational processes (Barsade, 2002). Emotions evolve dynamically in changing relational contexts through unfolding meaning construction (Garvey and Silva, 2010). During conversations about the change, people tune into the emotional experiences of those they are socially attached to (Schore, 2000) and co-create emotional and behavioural patterns (Garvey and Silva, 2010).

RDT conceptualises organizational change as a series of interrelated discursive struggles or communicative tensions where internal tensions occur between people in dyads and external tensions occur when members of the dyad interact within (or identify with) larger social units (Dumlao and Janke, 2012; Rawlins, 1992). There are inherent communicative tensions and differences between relating parties constructing meaning about the change. RDT refers to three fundamental communicative tensions filled with contradictory systems of meaning that occur in all developing relationships: autonomy-connection, novelty-predictability, and openness-closedness (Baxter and Braithwaite, 2009; Baxter and Montgomery, 1996). Multiple communicative tensions are likely to exist in relation to a given "bipolar feature" (Baxter and Montgomery, 1996, p. 9). For example, Baxter and Montgomery (1996) found that struggles in meaning about certainty could yield interrelated communicative tensions, such as certainty-unpredictability, certainty-novelty, certaintymystery, or certainty-excitement. Communicative tensions can also involve diachronic or synchronic interplay or both (Baxter, 2011). Diachronic interplay refers to communicative tensions that emerge over time and across contexts. For example, communicative practices that shift the emphasis onto the other pole of the certainty dyad during an organizational change can redefine existing employeeemployer relationships and even the meaning of work itself. Synchronic interplay refers to the merging of communicative tensions to create new meaning. 
Communicative tensions are not necessarily problems or breakdowns in human communicative processes, but a natural part of social and organizational life (Baxter and Montgomery, 1996; van de Ven and Poole, 1995). In fact, these tensions are likely to exist in organizations at both interactional and contextual levels. Interpersonal or group-related communicative tensions are viewed here as interactional or relational, while those due to strategy, structures or policies that influence people and groups are viewed as contextual (Altman, 1993; Rawlins, 1992). At the contextual level, communicative tensions arise due to the inter-organizational, organizational, unit-level structures and cultures that shape the context in which employees work. Thus, RDT can be viewed as a multilevel lens that can facilitate a multilevel analysis.

The praxis concept from RDT provides insights into how people negotiate on-going communicative tensions. In relationships, praxis or communicative practices can vary from denial to disorientation to conversations seeking balance and integration (Readers can refer to Baxter and Montgomery (1996) for a more in-depth overview). The organizational literature reviewed suggests multiple communicative practices to respond to communicative tensions: from select, segment, neutralize, reframe to withdraw (Gibbs, 2009; Tracy, 2004, Seo et al., 2004). Tracy (2004) elucidates three negative communicative practices common in organizations: selecting one dominant pole (switching from one pole to another based on time, target, or topic); source splitting, that is dividing oppositions among several people (e.g. playing 'good cop-bad cop'); and treating tensions as pragmatic paradoxes or double binds. These tensions can lead to negative outcomes, such as withdrawal and paranoia. Withdrawal involves removing oneself from a co-worker's or manager's presence or becoming silent and refusing to participate in a conversation (Gibbs, 2009). Seo, Putnam, and Bartunek (2004) suggest two additional negative communicative practices: integration (combining both poles using force) and transcendence (or transforming dichotomies) through recalibration or reframing. Researchers have also offered useful positive communicative practices for managing tensions. Complementary dialectics can lead to positive outcomes by walking an empathetic line, balancing priorities, and employing creative performances (Tracy, 2004). Seo, Putnam, and Bartunek (2004) propose connection (addressing 'both-and' possibilities) as a more complex way of negotiating 
communicative tensions (treating dualities as mutually reinforcing in order to address both poles of the tension).

Communicative tensions are also present when relational parties communicatively negotiate the interplay of contradictory meanings brought about by turning point events. RDT is useful for understanding these turning points (Erbert et al., 2005). Turning points refer to specific and concrete transformative events that positively or negatively alter the development of relationships (Baxter and Pittman, 2001). Baxter et al. (1999) identify four categories of turning points: intrapersonal (when a person evaluates the relationship against some ideal standard or norm); interpersonal (interactions between relational parties); social (interactions involving other parties in the social network); and contextual (forces external to the relating parties that are beyond their control). The turning point concept can be used to examine the sequence of events that employees communicatively remember to mark the trajectory of their relationships and to understand whether these events push their relationships with the employer toward greater or lesser commitment and satisfaction (Baxter and Pittman, 2001).

RDT highlights the importance of relating parties navigating through the change to find shared meaning through positive communicative practices. It will serve as an initial sensitising framework to deepen our understanding of how contextual and relational communicative tensions unfolded during a major change to an IT unit. Sensitising concepts, such as communicative tensions, turning point events, and communicative practices, will be brought to bear in analysing the case. This study builds on this literature by viewing a pattern of collective employee turnover during an IS organizational change as a social process involving different communicative practices in response to contextual and relational communicative tensions. 


\section{Research Method}

In this section, the case study context is introduced. This is followed by the description of the data collection process, and the analysis method used.

\subsection{Case Context: Streamlining the IS Organization}

This study presents a historical account of an IT unit that struggled to retain many of its staff during an organizational change. The importance of historical research in IS has been noted by Mason and colleagues (Mason et al., 1997). They argue that a historical study can shed light on the shaping of key events by focusing on the uniqueness of human experiences in organizational settings. Accounts of past events serve, not only as historical record of what happened during a certain period in time, but also help researchers to make sense of and explain contemporary phenomena (Mcgrath, 2007; Porra et al., 2014).

Following the Lee and Baskerville (2003) framework of research methods, this historical study associates a rich description of a unique case with theory - an interplay between theory and an empirical account. A broad theoretical perspective - in this case, relational dialectical theory focuses the historical narrative on particular events. The analysis then associates insights from the historical case with the theory to work out a theoretical perspective on the more specific research issue of communicative tensions in a IT unit change that can culminate into collective turnover. Thus, this case study narrative presents a time line of events consistent with the description of the historical method by Mason et al. (1997). This study draws from an 18-month field study of an IT unit in a large healthcare insurance organization (to be referred to as Healthco ${ }^{4}$ ). In March 2005, Healthco's business executives began raising a number of questions about their e-Health unit.

The story of the e-Health unit is typical of many IT units that need to change over time in order to survive. e-Health began with its use of Internet technologies in 1996 with a team of 5 employees. By

\footnotetext{
${ }^{4}$ Pseudonyms are used for all organizational entities and participants to ensure confidentiality.
} 
2000, with the rise of dotcom, it had grown to more than 50 employees. The Head of e-Health, at 32, was among the oldest. e-Health was composed of 5 main workgroups of 6-8 team members responsible for delivering functionality for particular communities: customers, intermediaries (brokers), employers, and partners (hospitals and healthcare practitioners). There was also a bulk email correspondence team and a special projects team. The bulk correspondence team was responsible for sending out electronic claims statements and other bulk notifications, while the special projects team was responsible for larger e-commerce processes, such as research and development, security, registration, document and content management, and developing interfaces to the back-end systems.

These teams, led by community heads, were composed of business analysts, architects and developers. Senior business analysts and business analysts (BAs) liaised with the business units and were responsible for establishing requirements and specifying the system design for the developers. The developers were skilled in Java and were responsible for coding the software application logic and the interfaces with the front-end and back-end systems. A small team of graphic developers reporting to a graphics manager with skills in HTML and Java Scripting were responsible for coding the user interface logic. They operated as a service function to the other teams. There were also two project managers responsible for overseeing and reporting on the status of projects. In 2005, two additional teams were added to support a number of new initiatives for the UK and US market. The aim was to create a platform for back office support for the two international joint ventures (JVs). In addition, the JV's call centre service and web development projects were to operate from South Africa. By 2005, e-Health had grown to more than 100 people.

As a result of the rapid growth in the local market and the increasing demands of the UK JV partner and the regulator, Healthco began to review and optimise some of its key IT organisational work processes. Customers were being supported by a range of channels in the so called front-office functions, such as the call centre, intermediary, walk-in centres, and the Internet. Providing this flexibility for its customers meant that the organisation had to integrate these channels more tightly 
into the back-office organisation where the core production processes were being managed. The managing director (MD) called for an intensive focus on streamlining IT and e-Health in particular.

In response, the IT executive commitee (IT Exco) proposed that significant efficiencies could be gained by closely integrating the various front-end channels, such as those managed by e-Health, with the back-office. There were two schools of thought, driven by the two rival unit heads (e-Health and Health Systems), on how the two units should be reorganized to support this goal. This research focuses on the aftermath of the 'streamlining' announcement made by the chief information officer (CIO) in September 2005, and specifically the response by a group of staff to leave the organization.

\subsection{Data Collection}

The goal of this research is to understand and describe the process by which an IT organizational change led to collective turnover. This type of research relies on qualitative data. Following Klein and Myers (1999), organizational change is best understood by analysing informants' social constructions through language and shared meanings. While this study shares some of the assumptions of interpretivism by focusing on situated understanding and meanings, and local emergence (Myers and Klein, 1999), it emphasizes dissensus (Deetz, 1996). In other words, unlike interpretive approaches that tend to presuppose a stable, consensual, unified, and shared conception of meaning and organizational culture (Baxter, 2011; Walsham, 1995), RDT's dialogical perspective regards meaning-making as fragmented, contested, tensional, and multivocal (Baxter and Braithwaite, 2009). Murphy captures a similar sense of dialogism to Bakhtin by articulating it as a lens "destructive of neat systems and ordered structures, and compatible with the notion of a social universe that has neither fixity or solid boundaries" (1971, p. 90). Identifying the interrelated communicative tensions is therefore a central step in analysing the data (Baxter, 2011).

Data was collected through in-depth interviews, participant observation, documents, and email. This study focuses primarily on interview data. Interviews are suitable for tension-centred studies as it 
recorded the various interpretations of events and the contested meanings of such events by participants. Furthermore, interviews are useful for documenting the communicative tensions experienced by participants and for gaining insight into the communicative practices through which they negotiate such tensions. The field research for the case study was carried out in two main periods between 2005 and 2006. A total of 25 semistructured interviews were conducted on site. Seven managers and 15 staff members from the e-Health division participated in the study (See Table 1 for a summary profile of interview participants). The interviews lasted between 45-60 minutes with each respondent. All interviews were tape-recorded and many were transcribed. Field notes of observations and interactions were also kept. This was supplemented by secondary data in the form of internal documents, management reports, prior research via internal and external parties, presentations, the organisation's publications, technical documents and internal reports. Relevant questions from the interview guide included previous and current roles and responsibilities, the communication of the change, how the work environment was changing, challenges and benefits of the change, the rumours and stories that were circulating, and how their colleagues were (staff, management) responding to the change. In the course of questioning, the prevalent theme of tensions became apparent and subsequent questions devoted greater attention to such issues.

\subsection{Data Analysis}

The data were analysed using ATLAS.ti content analysis software. The constant comparison method was used (Strauss and Corbin, 1998). In the first analytical step, line-by-line coding was performed to identify emergent codes, such as 'external stakeholder pressure'; 'inter-divisional rivalry', and 'staff uncertainty'. In the second iteration of coding, RDT concepts were used as sensitizing devices and 'put into conversation' with locally emergent meanings (Baxter and Braithwaite, 2009, p. 8). These codes were linked to broader communicative tensions in the form of interrelated dyads, which were highlighted and analysed more closely. For example, the primary tension related to the "staff uncertainty' code was translated into a larger system of meaning referred to as the 'stability versus change' dyad. Through building these codes and examining their related excerpts, various sub- 
tensions were identified (distinctive versus conventional and excitement versus predictability dyads). In the third step, sub-tensions were grouped together in families based on the primary tensions they revealed. For instance, the two sub-tensions mentioned above were grouped into a primary tension called the stability versus change dyad. In the fourth step, sub-tensions were also grouped together into separate social units based on whether they revealed contextual or relational tensions: for instance, distinctive versus conventional was grouped into contextual tensions while excitement versus predictability was grouped into relational tensions. Some of the tensions were reworded to accurately reflect the organizational context. For example, the autonomy versus connection tension in relational dialectics research (Baxter and Braithwaite, 2009; Baxter and Montgomery, 1996) was represented as alignment versus autonomy.

Excerpts were analysed to identify how managers and staff responded to each set of communicative tensions. For instance, withdrawal was a noticeable response from staff who later resigned. Major turning-points were also identified during these steps. After multiple iterations of these four coding steps, a larger thematic structure emerged, which will be discussed in the following section (a table with sample codes and quotes is available on request from the author). This analysis approach revealed the turning point events during the change, the sets of sub-tensions within larger primary communicative tensions and social unit categories, and the communicative practices of managers and staff, which provided the basis for the emergent theoretical model. Next, sufficient material is presented for the reader to assess the plausibility and coherence of these interpretations (Myers and Klein, 1999).

Table 1 Summary of case

\begin{tabular}{|c|c|c|}
\hline $\begin{array}{l}\text { Informants level } \\
\text { and position }\end{array}$ & Senior Management & $\begin{array}{l}\text { COO International Operations, Head of CIS, } \\
\text { Community Head, Operations Manager, Project } \\
\text { Manager, Support Staff }\end{array}$ \\
\hline
\end{tabular}

Architecture

Analysts
Chief Architect, System Architects

Senior Business Analyst, Systems Analyst, Business Analyst, Usability Analyst 


\section{Systems Developers Senior Developer, Developers \\ Graphics Team Graphics Manager, Graphics Developer}

25 semi structured interviews with 22 staff members Other *

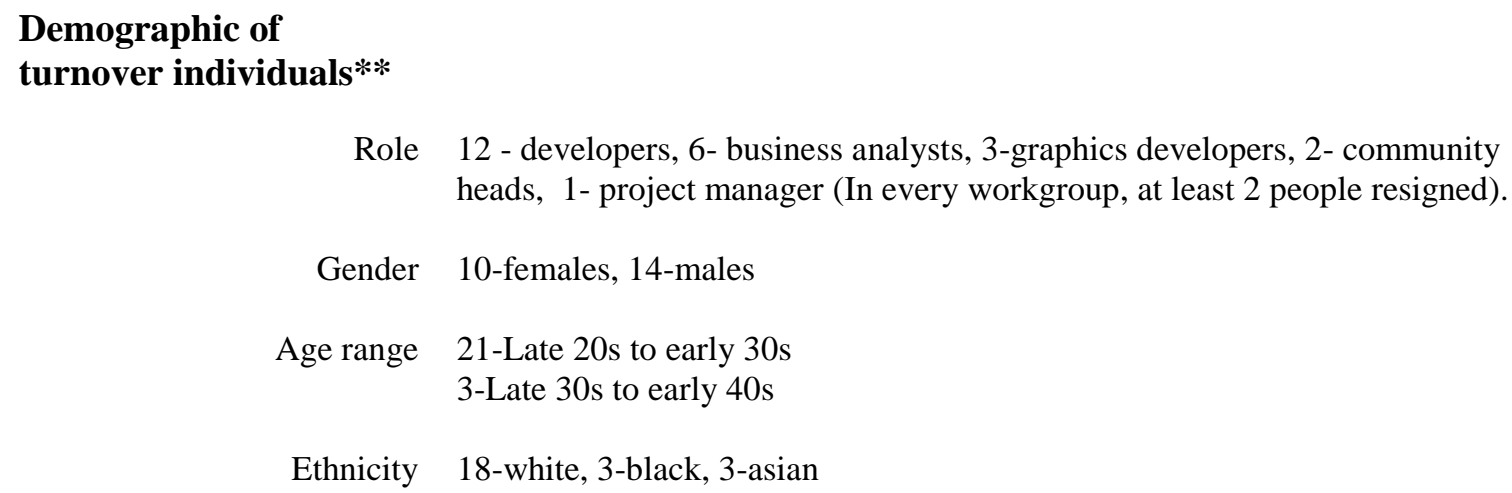

*Other refers to email correspondence, observations and informal discussions

** Refers to 24 departures two months after the annoucement. There were subsequently more departures.

\section{Results: Contextual and relational communicative tensions and collective turnover}

This historical case account of an IS organizational change provides evidence that communicative tensions at the contextual and relational levels are linked to a collective turnover cluster pattern that emerged at e-Health. Particular attention is paid to primary communicative tensions and related subtensions between managers and employees as well as their communicative practices.

\subsection{Alignment versus autonomy tensions in IS organizational change}

A key primary communicative tension that manifested itself through all levels of Healthco at the time involved enabling alignment while preserving autonomy. A related contextual sub-tension involved complying with strategic stakeholders while remaining independent. This tension spread to the IT units where the IT Exco had to realign to deliver more projects with more formality and fewer resources. Given their combative historical relations with Health Systems, e-Health struggled between 
sub-tensions of collaboration versus freedom. This tension manifested itself through e-Health's distinctive working style, leadership and technology culture.

Contextual sub-tension: Compliance versus Independence

The first communicative tension at the contextual level lies at the intersection of compliance and independence. This strategic tension involved complying with the expectations of two external stakeholders: the regulator and the UK JV partner. First, Healthco could not defy the local regulator's insistence to comply with higher reserve (solvency) requirements, lower administration costs, and lower healthcare insurance inflation. Second, Healthco had to comply with the IT governance practices and standards expected by their 'respected' JV partner to achieve their strategic goal of spreading its international footprint. While these priorities were not in direct conflict, fulfilling them simultaneously presented the dialectical tension in the form of 'both-and' (Putnam, 2004). Larry, the managing director (MD) of Healthco, explained in a shareholders report:

Over the past year, we have again focused intensively on streamlining the operational aspects of our business. Our strategy has been two-pronged - first, improving the technology and ecommerce capability...

The MD chose to negotiate the choice point between compliance and independence by focusing on 'streamlining' IT, as opposed to the business pole.

Contextual sub-tension: Agility versus formality

The second communicative tension at the contextual level lies at the intersection of agile versus formal. IT units had to contend with a contextual communicative sub-tension of aligning more closely to each other to support Healthco's rapidly growing local market and in its newly envisaged UK international operations, while prudently managing escalating staff numbers. Business executives 
were raising a number of questions about the size of IT in general and its overall productivity. The size of e-Health and the related value it was realising received increasing scrutiny. Gordon, a project manager for e-Health, explained the selective focus of the executives:

I mean, from the business side now, the guys would really question, you know, 400 software developers (referring to overall Group IT). What do guys actually deliver? Why don't we often get to do all the stuff that we commit to upfront?

Meanwhile, there was this sense that a lot of the system components should be sharable and reusable, and that the IT units could achieve faster and more predictable deliveries and better economies of scale in the form of joint systems design and development, and shared testing and quality control procedures. This information filtered through to the e-Health divison, as suggested by this neutral comment provided by Daniel, one of the senior system architects:

Well, there are some initiatives that are happening with the company... Healthco, where there is a climate of give a little more. There is this whole globalisation thing and there has been a realisation that the systems needed to be a little more generic, and a lot more flexible, scalable...

Meanwhile, to keep faith with the JV partners, a more disciplined approach to systems development was being enforced. e-Health now had to conform to many of Health Systems' formal standards.

Relational sub-tension: collaboration versus freedom

The first communicative tension at the relational level lies at the intersection of collaboration versus freedom. This relational sub-tension was evident due to e-Health staff finding it difficult to negotiate between being more collaborative and remaining independent from their rival. For a long time, they had operated in an entrepreneurial mode, without the bureaucracy of their rival unit. Not suprisingly, 
the relationship between the two units was combative. Reflecting on when e-Health began, Marie recalled in an open and somewhat balanced manner:

I think we were sort of seen as, call it the interloper ja that's what we were ... and I think we sort of came in and expected them all to drop everything to give us what we needed. We were dependent on some of these systems. It's like okay you have to deliver this for us. You know so we weren't part of Systems, and also the departments were also treated differently, like eHealth, in the early days we had our own chill room, it might seem silly, we did not go to the systems functions, we had our own functions...

Even though e-Health was 'dependent' on Health Systems, this quote reveals the intergroup tensions and the 'us' versus 'them' mentality between the two units. The 'traditional' staff members treated eHealth with their informal working style and separate socializing rituals as a foreigner, but e-Health continuted with their superior attitude and dismissive and 'arrogant' culture. Gyles, a senior business analyst, points to the estranged relationship between the two unit leaders as another reason for the combative nature of this relationship.

There was competition between the two teams on many levels. At the top level, Tom and Len both were competing to be Don's (CIO) understudy. Len is the more conservative, handson, cost conscious IT manager, whereas Tom is a big ideas, big budget, silicon-valley type of persona.

The quote by Gyles above hints at the opposing technology cultures appropriated by the two units. Martin, a long serving community head, confirms that the difference between the two cultures was not restricted to working and leadership styles, but also included different values and norms concerning technology. His one-sided quote stigmatizes the back-end developers and also points to the political struggle e-Health faced in pursuing a distinctive technology strategy: 
Healthco always has been a mess of technology types, especially in the development environment (referring to Health Systems). A lot of these were not industry standard type of products such as Magic and so had a very particular type of developer and mind-set associated with it. With e-Health we very much tried to follow the industry standards and use what at that stage would have been best of breed technology offerings which we did but not without huge and consistent resistance from other key players.

The IT Exco called for a reorganization to achieve better alignment and synergy between these two rival units. However, this meant overcoming culturally and historically strained relational tensions. The intense rivalry between the two IT units, hinted at here, would later limit the ability of many eHealth employees to react to workplace tensions in emotionally healthy ways.

\subsection{Stability versus change tensions in organizational change}

A second primary communicative tension emerging from the data was the stability versus change tension. This tension was evident by the way in which the two rival unit leaders imposed contrasting approaches that sought to elevate their unit's distinctive capabilities, the uncertainty about the way the rival teams were to operate together as well as the business areas and the technologies they would support. Consequently, there was this growing tension among many e-Health staff, stemming from dilemmas over excitement versus predictability, in the new working environment.

\section{Contextual sub-tension: Distinctive versus conventional}

The third dialectical communicative tension at the contextual level lies at the intersection of distinctive versus conventional. The IT Exco believed that significant efficiencies could be gained by closely integrating the various front-end channels with the back-office. There were two opposing schools of thought, driven by the two rival unit heads, on how the two ends should be reorganized to support this goal. The models are shown in Figure 1. In model A, the development team would apply 
their skills to both the front-end and back-end development for a specific business area (Health Systems view), whereas in model B, teams would specialise either with front-end or back-end development (e-Health view).

The first turning point was the announcement of this change. All the affected units were called together into the auditorium and the CIO presented for 20 minutes. He announced that over the next few months Model A and Model B were to co-exist and some employees could opt to work for Model A and others for Model B. Those staff members with back-end skills would move to Health Systems, and the staff with front-end and usability skills would be moved into the new Customer Interaction Systems (CIS) unit.

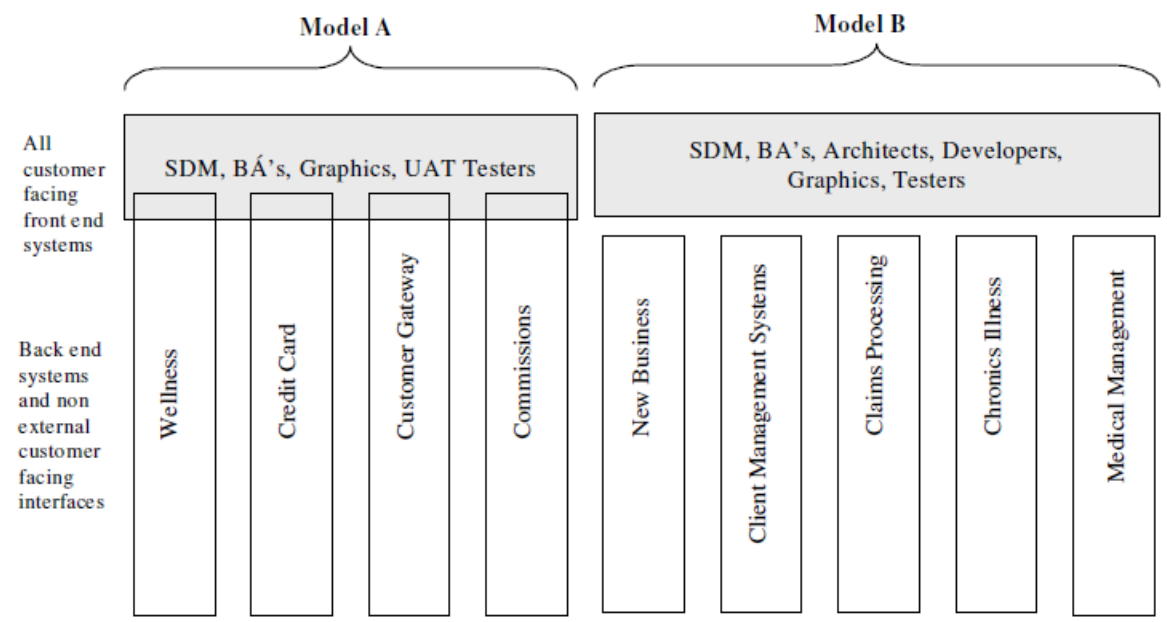

Figure 1. Proposed opposing IT reorganisation models Source: (Adapted to maintain anonymity) Internal change presentation (2005)

This announcement coincided with the second turning point - staff were informed that the former eHealth executive was being promoted and a new executive was being appointed to lead CIS. As one interviewee put it, the proposed reorganization announced by the $\mathrm{CIO}$, was disorienting:

But that was almost like an announcement and then you are expected to change. So that type of change is viewed, as like, you know, like something has gone horribly wrong. We are turning this thing on its head and we are going to move forward. 
At the same time, other employees viewed this turning point event as a 'positive shock' (Holtom et al., 2005). For example, another informant stated:

You know it might seem sudden but I think it has been going on for a while. We had two teams. For example healthstyle has always been split into two teams.

While many staff members felt uncertain, e-Health's managers dealt with the distinctive versus conventional tension by reframing themselves as Healthco's overall front-end custodians. They were negotiating to further elevate the distinctive status of e-Heath with the following kinds of statements. The previous Head of e-Health, Tom, stated:

One of the things that e-Health does particularly well, which maybe more an art than a science is the softer elements of the channel. How to position, how to message, how to design the user interfaces. Now all of those are steeped in something that is not well understood by the traditional environment. And I think maybe as a natural consequence of that there is almost a resistance or true prejudice against them for this and they understand and deduce that either it is not necessary, or potentially there is a threat associated with it.

His incumbent, Shirley, agreed with this reframing, stating:

And I think that that is why for the internal systems the user interface is not geared around what is the interaction that is taking place, and how do I need to present things. It is rather about, here is the product stuff and then make it work in terms of your interaction... But it is a hot debate at the moment.

Both leaders were engaging in identity entrepreneurship (Steffens et al., 2014). They embraced the change by asserting CIS's competency in usability. They appealed to CIS's distinctive capability to enhance 'user experience' and argued that all of Healthco's systems could benefit from this approach. In other words, the call centres (the domain of the 'traditional' Health Systems) would also benefit. In 
effect, the legitimacy of conventional 'back-end' systems staff being able to do this innovative frontend work was being explicitly challenged.

\section{Relational sub-tension: Excitement versus predictability}

The second communicative tension at the relational level lies at the intersection of excitement versus predictability. While some e-Health employees faced an irresolvable tension in how to respond to the change, others were excited and reaffirmed management's position. Daniel said:

What actually happened was that business, Joe (business unit executive), and the rest of the call centre people really said, 'look, but, look what is happening on e-Health. You log on and without clicking, you are actually seeing the entire profile. You see the guy's health plans, his life policy, Wellness, all of that, Cards, all are on-stream', you know. 'Why can't we have the same kind of stuff in Paradigm [the call centre application]'?

Those at the other pole of the tension grumbled about their new customer experience role as "fluffy stuff". The idea of running around "complaining about pedantic stuff, like colour and shapes, and whether or not something makes sense from a wording perspective" did not appeal to many of the business analysts. As Mario said, 'The BAs don't know what the most intuitive way to structure a page is cos' they never had to deal with that. That is what the graphics team did...'. Despite the optimism of their managers, many e-Health staff appeared to be having difficulty making sense of their newly imposed unit and occupational identity. Matt, a graphics designer, mentioned: 'I see usability as a purely pragmatic thing that, you know, as a, as a graphic designer, you have a feel for it anyway. And now it seems a huge departure, a whole bag of resources being positioned under this one heading, usability.' 
Meanwhile, Glen, a business analyst, complained that in the new working environment, the "family feel" of e-Health was being replaced by a "corporate feel":

It has become more corporate; they started bringing in a lot more processes, just in terms of doing anything really, taking things live, making changes to databases, from getting sign off... Maybe it can be seen as a good thing but it also slows things down a helluva lot. From a time capturing time perspective they have gotten stricter with that, how often people capture time, to what detail people capture time, and I don't see that stopping anytime soon. In fact I see it becoming more and more corporate.

When probed further about the change, he said: 'For me the main changes, it felt like a small company when I first started here, people ran on adrenaline, they were processes in place but you could break them, there wasn't a lot of red tape, which I enjoyed because that is the kind of environment I prefer working in. I think slowly that culture has changed.' This excerpt is evidence of how the dominant discourse of novelty and fun of the past had now been replaced with predictability and control.

Garret, who was moved to the testing team, confirms some of the negativity felt, but also acknowledges the benefits of working in a stable environment.

And, you know, testing we've recently adopted a new go-live... And, it has been quite interesting, because initially I think everyone was quite a bit negative. Because what they have done is, they have made, every two weeks on the Friday we have the go-live now. If there are problems over the weekend, it means that guys have a little bit of extra time, come in early Friday mornings, probably stay late Friday nights... But it has definitely created a more stable environment. 
While the new formal testing process created a more stable environment and better alignment between the different development teams, it was interfering with the personal lives of staff.

There was now a perceived shift in e-Health's fairly loose 'family' culture being replaced with a 'rigid' bureaucratic culture. Tom, the previous e-Health head, made sense of it as follows:

That is a function of Healthco being a different organisation. That's the function of Healthco having to account for close to 1.8 million lives. You can't do things, the analogy; you can't have kids running around a nuclear reactor. And then if it's not bureaucratic then it tends to kill people.

When probed further about 'fun' in the new organization, he said: 'No, I mean, I do not see that (referring to fun and bureaucracy) as being mutually exclusive. If fun is defined by being flippant about how you manage a very big, complex environment, then I would say yes, fun is going to fall by the wayside. If fun is defined as achieving a major milestone and you are continually pushing the boundaries, doing new stuff, doing new and interesting things, meeting new requirements. I don't see, I don't see any trade-off.' The excerpt demonstrates how the IT leader denied the loss of fun and reframed the tension. In his mind the 'fun versus bureaucracy' contrast need not be regarded as opposites. Although reframing helped the leader personally come to terms with the re-organizing, a number of staff were clearly dissatisfied. Part of the reason was that managers, such as Tom, were not openly discussing their perspectives with staff.

\subsection{Expression versus suppression tensions in IS organizational change}

The third primary communicative tension was one of expression versus suppression, and relates to the transparency of the communication climate within the IT division. It consisted of related contextual sub-tension of disclosure versus concealment, and relational sub-tension of openness versus closedness. 
Contextual sub-tension: Disclosure versus concealment

The fourth dialectical tension at the contextual level lies at the intersection of disclosure versus concealment. When the proposed reorganization was communicated by the $\mathrm{CIO}$, e-Health managers were caught in a double bind between whether or not to communicate details about the anticipated changes to employees. One of the older systems architects, Ivan, described the tension by normalising the cloak-and-dagger response taken by e-Health managers:

It's a war in the beginning, it's a business war... and like in any war, the general cannot expose his strategy to the army at any stage, at least at the beginning... especially in an environment like this if you want to achieve anything...

After the announcement by the CIO, the new e-Health manager chose to skirt the discursive struggle and not to discuss the changes openly with employees. There seemed to be two reasons for this: First, she was reticent to communicate something that later turned out to be incorrect. Second, there was a general concern that staff may choose to leave the organization, rather than endure the painful change process. Wayne, one of the longstanding members of the team, confirms management's reticence to discuss details about the change and the staff's push for more openness and involvement:

The next time that things were discussed was probably our staff meeting... but it was sort of brushed over, minimal time spent. But I think the expectation was that it is happening in the various teams.

Relational sub-tensions: Interact versus disengage

The third communicative tension at the relational level lies at the intersection of interact versus disengage. The contextual tension above, played out in the relational tensions between managers and 
staff. Shaun, on the graphics team, responded negatively to the second turning point - Shirley's appointment - by commenting on her unwillingness to interact with staff. Shaun's quote also signals the growing rift between e-Health managers and the team:

It's a lot colder. She is not as relaxed as Tom was. She seems a lot more formal than Tom was. Tom was a much more informal person. You still knew he was in charge but it wasn't like...Shirley is almost unapproachable. ....She's more in with the community heads then she is with people a little bit lower down the scale, you know so just my impression.

On the other hand, some staff members walked the empathetic line and showed more nurturing emotions when reflecting on the new manager. Lara, a support staff member, mentioned:

I think Shirley has got very big shoes to fill. Firstly in the workplace it is not easy being a woman and being such a senior manager and its tough, it's tough to get the respect of upper management ... I feel sorry for her, I think it is tough.

Meanwhile, Donna, one of the opinion leaders in the unit, was reprimanded for expressing a negative opinion about the change. The following brief sentences from the field notes states: "Sharon mentioned an incident with a senior manager, where Donna was "shouted at" for expressing her opinion about the change. According to Sharon, Donna never felt comfortable ever since the incident and later resigned"

The third turning point event was when some staff were unilaterally 'pushed' into joining the backend systems. They were upset that e-Health managers managed to retain their positions while they were forced to move. Wayne, one of the senior business analysts, noting the perceived unfairness, said: 'I think they believe they have been sold out. The move itself wasn't very well thought-out and the processes... I think the emphasis of the thinking was more of how it was going to work for business, as opposed to how it would be perceived by the individuals that were involved.' 
Gordon, the project manager (who retained his position) at CIS, alludes to the personal tension he experienced when asked to be a 'bad cop' in the transfer process. Preferring to show more empathy and nurturing emotions, Gordon discusses his struggle with management's emotional ambivalence and use of source splitting as a response:

I mean, you know, some of the people driving the change are maybe more hard-core than some of the people experiencing the change...yes, I think, I take flack from the fact that I take a soft approach.

Consequently, the low levels of interaction and confusion brought about by the forced transfers, led to debilitating emotional reactions, such as paranoia. There was this growing opinion among e-Health staff that Healthco was "putting a squeeze" on them. Although Healthco was not using the word, 'retrenchment', a lot of the staff expressed feeling insecure and began to leave.

\subsection{Individual and group withdrawal and exit strategies}

While some of the communicative tensions experienced within the e-Health teams were negotiated positively by some managers and staff, they were generally experienced negatively. Overall, many staff felt that the change was not being managed appropriately. They were specifically upset with the transactional communication style of their new unit leader, the job of specialising on front-end system design and delivery, and the forced transfer of team members to a once rival unit.

Relational sub-tension: Withdraw versus embrace

The fourth communicative tension at the relational level lies at the intersection of withdraw versus embrace, and is a culmination of the different contextual and relational communicative tensions 
discussed. These tensions jointly contributed to widespread dissatisfaction among e-Health staff. This is apparent by the negatively expressed emotions and fatalistic quote from Shaun, the graphics developer: 'I am personally not happy. I used to love e-Health, I used to love coming to work! Now I hate coming to work! I hate it!'. Many staff members, disoriented by the change, withdrew psychologically and became passive in their new roles. Some reacted by 'hiding' behind the new processes, as the following remarks by Glen confirms:

The business would ask me to do something that was not approved from a user perspective and I know what the focus is so I say no, I need a business spec please, and I need three people to sign it off which obviously delays it, and what it started to doing for me is that I can start hiding behind the process.

A quote by Marie also points to the feeling of increasing distrust with management:'We hide back what is happening from management, from everyone, and trying to sort it out as colleagues.' Glen and Marie were among the first to resign.

Contextual sub-tension: Permeable versus impermeable

The fifth communicative tension at the contextual level lies at the intersection of permeable versus impermeable. While the boundary conditions for finding placements was permeable for many, only a few felt it less permeable. There are two main reasons for this. First, South Africa is characterised as a developing country and IT skills are scarce. Second, Healthco is situated in, arguably, the IT capital, making location a minor issue in the job search. It is not surprising that a number of staff began to secure new placements within just 2 months of the announcement. As one of the staff members pointed out: ' it actually is a double whammy, because while you create unhappiness.. then, all the work you have done, to like attract the people that you are trying to attract, those very guys find it the easiest to move on.' 
An older male staff member stated: 'I think it is a reality for, maybe for, like, I don't know, some females around, some, like previously disadvantaged communities (referring to black and asian staff), it might be easier. And like the guys that are maybe moving on, or, you know, I don't think any of them have like the white males. Because it is just not, you can't find a job overnight.' His quote illustrates how the national regulatory context and social comparison process can also shape personal perceptions of boundary conditions. South Africa's government-regulated affirmative action policies privileges nonwhite male and female placements, especially in IT jobs that are dominated by white males. This quote subverts the fact that many single white males did resign (See Table 1). This denial was probably offered as a way to cope with the dissonance of not finding a suitable placement. This staff member also resigned within a short period.

\section{Relational sub-tension: Stay versus exit}

The fifth communicative tension at the personal level lies at the intersection of the stay versus exit decision. Mario, one of the loyal system architects, provides a sense of the negative emotional reactions of those who had resigned: 'We are short six developers and seven BAs. So out of all this movement we gained departments which is amazing and we are short a shit load of people.We are short six developers and seven BAs ...because of this change they chose to leave.... For them it's a bullshit job! Ja, leaving e-Health team, clearly, and what that really meant was that the people left over are fairly junior. Hopefully they will hire, they effectively got vacancies, they need to hire the skills.' Mario's quote gives us a sense of the shared mood of those who left. Significantly, those who left were clearly not emotionally tied to their newly imposed unit and occupational identity. Gordon, the project manager, who would later resign stated: 'I personally believe that a few people who moved on recently to resignation and I think there is probably, my expectation is that in the next two months, beginning of December and beginning of January, we will have a couple of more people leave. And I am convinced that is a knock-on effect from this change. And they wouldn't have left if it wasn't for this.' 
There were staff that supported the change, a few voluntarily transferred to other units, but many decided to leave. Within 2 months of the announcement around 25 staff members resigned. Many more employees resigned in the next two months. Seven months into the streamlining announcement, the CIS division was disbanded. Many of e-Health's reponsibilities reverted to the Health System's portfolio. Shortly thereafter, the name e-Health on the signage that stood near the lift on the 2 nd floor for almost 6 years was removed. Meanwhile, Healthco continues to expand successfully into the international market. Both the business and IS organization continue to change.

\subsection{Summary}

The findings identified several seemingly irresolvable communicative tensions during this changeinduced collective turnover. Table 2 summarizes the key tensions and their nested contextual and relational sub-tensions, from the strategic to the individual level, and the key communicative practices employed.

Table 2

Summary of contextual and relational communicative tensions and collective turnover

\begin{tabular}{|c|c|c|}
\hline Primary tension & $\begin{array}{l}\text { Contextual/Relational Sub- } \\
\text { tensions }\end{array}$ & $\begin{array}{l}\text { Organizational level, stakeholders, and key } \\
\text { communicative practices in response to tensions }\end{array}$ \\
\hline Past versus Present & $\begin{array}{l}\text { Dominant discourse at time A } \\
\text { Dominant discourse at time B }\end{array}$ & $\begin{array}{l}\text { Discourses that shaped the history of employer-employee } \\
\text { relationships. }\end{array}$ \\
\hline \multirow[t]{3}{*}{$\begin{array}{l}\text { Alignment versus } \\
\text { autonomy tensions }\end{array}$} & $\begin{array}{l}\text { Contextual: } \\
\text { Compliance versus independence }\end{array}$ & $\begin{array}{l}\text { Level: Strategic context; Interorganizational } \\
\text { Stakeholders: Regulator and JV Partner } \\
\text { Communicative practice (-): Top management were selective, } \\
\text { appealing to the strategic objectives to justify streamlining and } \\
\text { governance in IT. }\end{array}$ \\
\hline & $\begin{array}{l}\text { Contextual: } \\
\text { Agile versus formal }\end{array}$ & $\begin{array}{l}\text { Level: Interdivisional } \\
\text { Stakeholders: Business units and IT; IT units } \\
\text { Communicative practice (-): The Group CIO was selective, } \\
\text { appealing to the strategic objectives to realign IT. Manye- } \\
\text { Health staff were disoriented by the sudden announcement. }\end{array}$ \\
\hline & $\begin{array}{l}\text { Relational: } \\
\text { Collaboration versus freedom }\end{array}$ & $\begin{array}{l}\text { Level: Intergroup/Intragroup } \\
\text { Stakeholders: Staff } \\
\text { Communicative practice (-): Old guard e-Health staff were } \\
\text { selective, emphasising a combative relationship with Health } \\
\text { Systems. }\end{array}$ \\
\hline
\end{tabular}


Stability versus change tensions

Expression versus suppression tensions
Contextual:

Distinctive versus conventional

Relational:

Excitement versus predictability

Contextual:

Disclosure versus concealment

Relational:

Interact versus disengage

Relational:

Withdraw versus embrace

withdrawal and exit strategies
Contextual:

Permeable versus impermeable

Personal:

Stay versus leave
Level: Intergroup

Stakeholders: Unit leaders

Communicative practice (-): Unit leaders were selective, emphasising distinctive unit capabilities.

Level: Group

Stakeholders: $e$-Health staff

Communicative practice (-): Some e-Health staff were selective, emphasising the loss of the 'fun' culture and increasing bureaucracy while management denied or reframed the loss of fun

Level: Group

Stakeholders: Managers and e-health staff

Communicative practice (-): $e$-Health managers emphasising a closed communication climate neutralised opposition or selectively avoided discussing issues about the change. Some staff were selectively concealed information about the problems at work.

Level: Interpersonal

Stakeholders: New unit leader and e-health staff Communicative practice: The unit leader withdrew and chose not to interact too closely with lower level staff. Management also resorted to source splitting (i.e. playing 'good cop-bad cop').

Level: Group, interpersonal, personal

Stakeholders: $e$-Health staff

Communicative practice (-): Some dissatisfied e-Health staff psychologically withdrew from their work and interaction with their managers.

Level: Local job market, National labour regulations Stakeholders: $e$-Health staff

Communicative practice (-): Many senior staff expressed that finding placements was easy while a few expressed that it was slightly tougher.

Level: Personal

Stakeholders: $e$-Health staff

Behavioural response (-): Many experienced staff left, others transferred internally, and the majority of newer staff stayed at the firm.

Turning point 1(-): Group CIO announcement of change

Turning point 2(-): Appointment of new unit leader

Turning point 3(-): Forced staff transfer to rival unit

\section{Discussion of the results: Theoretical and practical implications}

Understanding how collective turnover of IT employees occurs during the same period as an IS organizational change is important, given the strategic importance of IT talent and the catastrophic consequences the losses of scarce human capital can have on the overall performance of the IS organization. In this section, the main findings of the study and the key contributions to the employee turnover and IS strategy literature are discussed. Second, this study provides the main managerial 
implications for employee retention management during times of IS organizational change. Finally, the study's main limitations and interesting avenues for future research are briefly discussed.

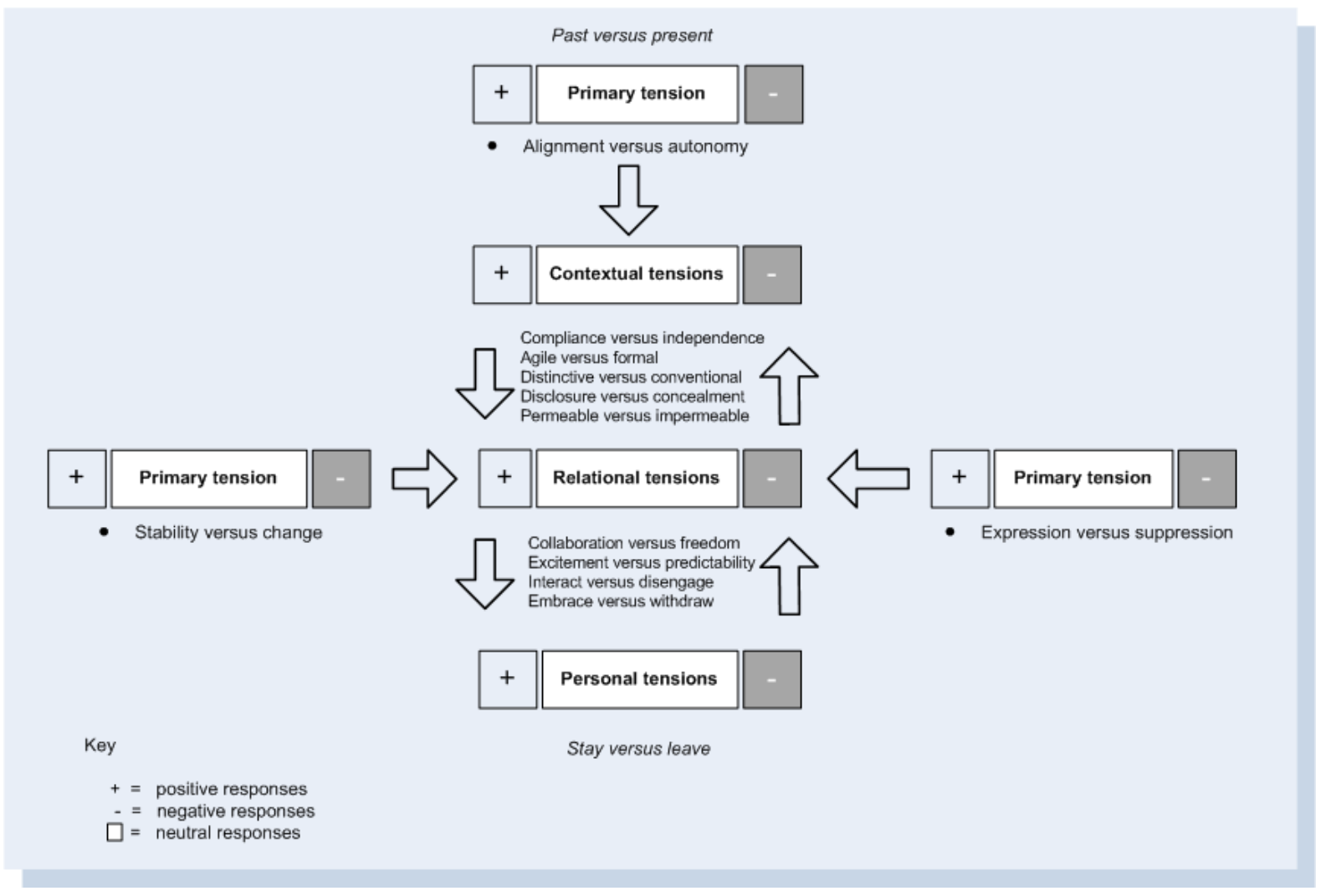

Figure 2. A communicative-tension model of change-induced collective turnover

\subsection{Implications for turnover theory: Relational and dialectical perspectives}

This study used a relational dialectical framework to explore the communicative tensions faced by employees during an IS organizational change. Based on the analysis of the case, this study develops a multi-layered communicative-tension model of change-induced collective voluntary turnover (CICVT) (see Figure 2). The proposed communicative-tension model responds to the call by Joseph et al. (2007) to be more sensitive to the multi-level context of IT turnover. In the model, CI-CVT is conceptualised more holistically as a context-specific and broader relational level phenomenon. 
Generally, the communicative-tension model of CI-CVT is similar to a few collective turnover process models that do exist (Bartunek et al., 2008; Felps et al., 2009). Both these models from the HR literature view collective turnover decisions as shared processes that arise from shared dissatisfaction. However, the communicative-tension model of CI-CVT's major shift is in revealing how seemingly irresolvable communicative tensions at broader relational levels provide the generative mechanism that gives employees the meanings that inform their turnover decisions. Communicative tension is therefore an important collective construct that provides the frames of meaning for collective employee action.

Table 2 shows that the model also moves beyond the typical communicative tensions faced in everyday personal relationships, proposed by Baxter and Montgomery (1996). This study extends prior relational dialectics research (Baxter and Montgomery, 1996; Gibbs, 2009; Jian, 2007) by specifying communicative tensions that are more salient to organizational change. For example, the autonomy-alignment dialectic referred to in the model was more faithful to the strategic context reflected in the empirical data (de Rond and Bouchikhi, 2004). Furthermore, the analysis shows the extent to which communicative tensions observed at one level of analysis was interrelated with communicative tensions at other levels of analysis (Altman, 1993; Baxter and Braithwaite, 2009). For example, e-Health employees complained that the increasing need for compliance at the organizational level in Healthco lessened the degree of freedom they could exercise at their workgroup level. The model, therefore, offers a way for turnover researchers to move beyond an individual level of analysis to assess turnover in more holistic ways. As shown in Table 2, the proposed model links multiple levels of analysis (e.g. interpersonal, group, intergroup, organizational and interdivisional). More specifically, the communicative-tension model of CI-CVT deepens our understanding of how processes of communication and negotiation that occur during an organizational change culminate into collective turnover. Previous IT turnover studies have noted the importance of communication issues, but they tend to focus mainly on the communication inadequacies of supervisors (Allen et al., 2006; Hall et al., 2008). However, they tend to ignore the 
broader relations and inherent contradictions involved in communication practices across the organization.

Bartunek et al. (2008) took an important step towards clarifying the broader communicative aspects of collective turnover. Their escalating model of complaining behaviour from the HR literature suggests that a lack of supervisor support in resolving complaints or 'voice' is crucial in informing multiple members' voluntary turnover decision. Instead of viewing conflict as supervisor-against-staff, the proposed communicative-tension model emphasises discourse-against-discourse. This study, therefore, further develops the 'voice' approach by suggesting that it is the tensions brought about by competing discourses which result in shared dissatisfaction and motivates collective turnover decisions. Thus, the proposed communicative-tension model differs and improves upon the voice model in three important ways. First, the concept of 'voice' is broadened to include specific communicative tensions within relationships (internal) and the larger context in which the relationship exists (external). Second, the model focuses on interplay of competing discourses about the change and not just heard/unheard complaints that influence or produce the decision to leave. Third, the communicative-tension model assumes that some discourses are more dominant or central than other more marginalized discourses - that is, entrenched in discourses is the notion of power and inequality (Baxter and Braithwaite, 2009; Marabelli and Galliers, 2016).

Prior literature has shown that the context of an organizational change is novel and uncertainty inducing (Baron et al., 2001; Rafferty and Griffin, 2006), thus creating communicative tensions that are often difficult to overcome (Gibbs, 2009). As shown in Fig. 2, the impending change brought about a sense of uncertainty and loss that led many employees to converse negatively about the prospects of staying with the firm (centrifugal force); simultaneously, some employees conversed positively about the opportunities (centripetal force) and, therefore, their commitment to maintain their relationship and stay at the firm (Baxter and Montgomery, 1996). Table 2 summarizes the communicative tensions at a particular period in time at the different contextual and relational levels, the turning points in organizational relationships, the different communicative practices from 
stakeholders used to manage the tensions, the permeability of the local job market, and the appraisal of different employee stay, withdrawal and exit strategies. This study expands our conception of collective turnover by including broader contextual and relational level dynamics. The findings also illustrate the importance of control over meanings (Ford and Ford, 1995; Kyriakidou, 2011) as various groups compete to shape the interpretations of the organizational change and turning point events. At Healthco, the dominant institutional meanings worked to problematize taken for granted meanings of e-Health employees and neutralize oppositional interpretation to the change. Managers and staff were also guided by different sets of meanings. In the case, the new logic of the 'bureaucratic' organization was at odds with the historically situated logic of the 'entrepreneurial' IT unit constructed during the earlier selection, socialization and enculturation of e-Health's employees (Baron et al., 2001).

These findings also illustrate the importance of a longitudinal focus in collective turnover studies (Holtom et al., 2008). More specifically, the findings illustrate how time framed the interactional context for conversations about staying or leaving the firm. This suggests that collective turnover decisions can be influenced by the diachronic interplay between discourses that emerge over time. For example, at time A when e-Health was being formed, the organization emphasised one discourse for the unit (autonomy) while competing discourses were muted (alignment). At time B, the previously muted discourse (alignment) received emphasis and the previously dominant discourse (autonomy) was overlooked. The values and meanings implied by the new operating model, the new requisite skills and the changes to working relationships at time B created high levels of shared dissatisfaction in the e-Health unit (Baron et al., 2001).

The findings also reveal how the organizational change created a context in which talk about prior, existing, and future relationships with colleagues, workgroups and other units become more important (Kovoor-Misra, 2009; Rafferty and Griffin, 2006). For example, the data shows that employee turnover talk - that is, talk that informs employee decision to either stay or leave the changing organization - increased when one pole of the selected communicative tension prevailed over its counterpart (i.e., too much red tape and too little freedom). One of the experienced project managers 
even claimed that without the organizational change, turnover would not have occurred. Furthermore, many e-Health employees were also influenced by crucial conversations with colleagues who were already directly affected by the organizational change. For example, some staff members were being forcibly transferred to a rival unit whose bureaucratic culture was at odds with e-Health's 'family' culture (Baron et al., 2001). Thus, this study provides insights into the situation-specific nature of salient communicative tensions that construct the meaningful experience of and employee actions and interactions and turning point events.

Evident in the model is that change-induced collective turnover is also triggered by turning point events (Baxter and Pittman, 2001; Erbert et al., 2005). The concept of turning point events (Baxter and Pittman, 2001) complements the concept of shocks (Holtom et al., 2005; Goswami, 2014; Joseph et al., 2007) but provides concrete insights into how organizational relationships are altered by the change. The CI-CVT model also suggests that the sequence of turning point events may have contributed to different outcomes. For example, the appointment of a new leader who articulated a different set of values and norms at e-Health, before the transition was completed, played an important part in pushing some employee relationships towards lesser commitment to the unit and the overall Healthco organization.

It is not surprising that e-Health experienced turnover disproportionately from its most senior employees, confirming what Baron et al. (2001) refer to as "old guard disenchantment". This suggests that organizational change can have several meanings for employees and can be interpreted in multiple ways (Kyriakidou, 2011). For example, it was evident that employees who recently joined the IT unit generally advanced more positive and neutral responses about the communicative tensions and turning point events. Thus, many of the newer recruits did not share in the same meanings and dissatisfaction of the "old guard".

The findings summarised in Table 2 also indicate that managers, and subsequently employees, generally used negative communicative practices to manage communicative tensions. Most 
communicative tensions were negotiated by selecting one dominant pole. Other negative communicative practices included denial and source splitting. Positive communicative practices to negotiate the communicative tensions, such as walking an empathetic line, balancing priorities, and addressing both poles of the tension recommended by the literature, were notably absent (Gibbs, 2009; Tracy, 2004, Seo et al., 2004). These findings provide support for previous research that speaks to the poor communicative practices that managers commonly use to manage communicative tensions during an organizational change (Gibbs, 2009; Jian, 2007; Seo et al., 2004; Tracy, 2004). This study also extends prior research by identifying additional communicative practices managers and employees used to negotiate communicative tensions (such as selective avoidance and selective concealment). Selective avoidance refers to a manager's sensitivity to risk disclosing information when broached for information about the change. Interviewees described how managers did not have sufficient time to talk about change issues, but had sufficient time to talk about operational issues. Selective concealment refers to employees' attempts to conceal information and make deliberate omissions when engaging with their managers about the progress of the change. The interviewees described 'hiding' information as a result of increasing distrust with their managers (Burnes, 2006).

From this analysis, change-induced collective turnover can be defined as a context-specific and relational process, where multiple employees sharing similar meanings and experiences of dissatisfaction during a major organizational change, decision to leave emerged from the largely negative communicative practices that managers employed to negotiate communicative tensions. The findings suggest that employee withdrawal and collective turnover is more likely to result when managers apply negative communicative practices to negotiate change-induced communicative tensions and communicate turning point events. Nevertheless, if communication lines are open and tensions are negotiated, it seems plausible that more employees may respond positively to the change (Ford and Ford, 1995; Burnes, 2006). To conclude, managers could be more successful at retaining talented IS employees during an organizational change if emergent communicative tensions are managed as a shared project and are negotiated constructively by managers and employees. 
Change-induced collective turnover is a major risk facing changing IS organizations under conditions of permeable employment boundaries. IS organizations undergoing a major change risk depleting their most strategic asset, their human capital, if they fail to address communicative tensions. The change investigated in this study was particularly disruptive. The disproportionate losses in human and social capital eventually forced the organization to disband its IT unit. It is important for further research to explore change-induced collective turnover, and rather than just focusing on the individual level, to consider the extent to which these turnover decisions are influenced by broader contextual and relational dynamics. In addition, this study suggests the importance of investigating the communicative practices that leaders can adopt to successfully negotiate and resolve communicative tensions that exist across the different levels of the changing organization to mitigate the risk of heightened collective turnover.

The change-induced communicative-tension model proposed here also has theoretical and research implications beyond collective turnover studies in IT. For one, considering strategizing from a communicative-tensions perspective also has implications for IS strategy researchers interested in conceptualizing the rich relational dynamics in areas such as IS strategic alignment, IS competitive advantage, knowledge management, IS capability development, IS agility capabilities, digital business strategy implementation, and outsourcing (Peppard et al., 2014). For example, if researchers examine specific communicative-tensions in IS strategic alignment, they could reconceptualise the current, relatively sterile and mythical notion of alignment between business and IS strategy (Galliers, 1991). Alignment from a communicative-tensions perspective could be seen as a dynamic meaning-making enterprise between business and IT as conversation partners in a social process, involved in a constant struggle of negotiating synergistic meaning over opposing discourses at work.

To move beyond current conceptions, researchers could also consider alternative ways of conducting strategic IS research. IS scholars have, over the years, called for greater diversity in research approaches (Galliers and Land, 1987) beyond the traditional paradigmatic triad of positivistic, interpretive and critical research (Orlikowski and Baroudi, 1991). This study responds to this call by 
providing an example of the so-called fourth paradigmatic approach: the dialogical approach (Deetz, 1996). IS researchers willing to take the linguistic turn advocated by postmodernism could make further valuable contributions to understanding many strategic IS issues by considering their communicative processes. More specifically, by giving more attention to the micro analysis of communicative tensions expressed between business and IT as relating parties in transcribed conversations and texts, IS researchers can begin to conceptualise a number of strategic issues as communicative phenomena. Interpretive IS researchers, in particular, are urged to shift their focus from stability and consensus to the fragmented and contested nature of meaning-making that characterise many important IS practices.

Next, this communicative tension based conceptualisation of collective turnover raises a number of practical implications for IT employee talent retention during times of an IS organizational change.

\subsection{Practical implications: A dialogic and collaborative approach for retaining IT talent}

This study recommends positive communicative practices for practitioners to manage communicative tensions to mitigate collective turnover and manage the retention of IT talent. Retaining a group of experienced, creative and innovative IT employees can be complex, especially when they expect to be involved in co-creating the changing organization. As observed in the case study, a top down communication approach based on functional theories will not work well in complex and 'sticky' contexts. IT leaders who employ traditional problem-solving techniques or who frame their communication in "either/or" ways - where the meanings of dominant discourses are taken-forgranted - are more likely to worsen communicative-tensions, as they tend to over-focus on one pole to the neglect of the other. On the other hand, communicatively competent IT leaders sensitive to the history of their employees (their selection, socialization and enculturation) who employ a dialogic and collaborative approach by generating "both/and" solutions are more likely to be successful at retaining talent (Seo et al., 2004). For example, in the case study one of the communicative tensions was over 
"excitement" versus "predictability". In exploring this communicative tension, the generative question for the IT leader and the group could have been, "How can the organization be 'formal' and 'fun' at the same time?", or "How can the firm benefit from formality while holding on to the past benefits of ‘fun'?” From a dialectical perspective, to be communicatively competent, IT leaders should integrate oppositional views and capitalize on the synergy inherent within these tensions to keep their employees satisfied. Rather than avoid tensions or emphasise the benefit of one pole, they should emphasise the synergetic benefits of both poles. Since the IT leader needs to pay attention to both the organization's needs and the employee's needs, framing the change as "playing responsibly" is an example of a possible both/and solution that can emerge if the leaders in the case took the time and made the effort to engage their creative and innovative IT employees in such conversations. Using dialectics in the service of practitioners by suggesting that they work through communicative-tensions with their employees in emotionally healthy ways offers no guarantees of eliminating collective turnover. However, the overall humaneness of a dialogical and collaborative approach to change, in the author's view, offers a better answer to the IT talent retention challenge facing the changing IS organization. As a final reflection, limitations of the study and interesting avenues for future research are presented.

\subsection{Conclusion, limitations and future research}

This study provides an in-depth examination of a change-induced collective turnover at an IT unit. It has explicated a relatively comprehensive, multi-layered communicative-tension model to describe the processes that unfold into change-induced collective turnover. A major contribution of this paper was to respond to a lack of process studies on collective turnover, especially where dialectical forces feature prominently. The paper also contributed by framing these dialectical forces as communicative tensions at multiple levels in the organization to explain a change-induced collective turnover pattern. Beyond employee turnover and talent retention, a communicative tension perspective also has implications for IS researchers investigating social processes and communicative practices in other strategic areas. This paper also offered practitioners advice on how to communicate and negotiate 
more effectively during an organizational change in order to mitigate the risk of collective turnover. It would be fruitful if more turnover research in IT investigated the context of IS organizational change and offered a situation-specific understanding of collective turnover. Notwithstanding, the first limitation of this study is that its findings are based on an in-depth examination of one organization. Particular characteristics of the organization may have influenced the findings. Furthermore, although the strength and interest of the proposed communicative-tension model developed here is in understanding situated communication, the development of a more general understanding of communicative tensions in change-induced collective turnover may require additional case studies in other organizations. A second limitation is related to the historical evidence and the retrospective data analysis strategy adopted. While this historical approach revealed some interesting aspects of how change-induced collective turnover developed over time, the evidence did contain some gaps. For one, it provided limited micro-level understanding of some of the intimate relational processes among some of the co-workers who left. A related limitation is that the employees of the rival unit were not interviewed for verification. Future real-time research, generating fine grained insights into co-worker and rival IT unit employee relationships, will be invaluable in other change-induced contexts. Despite these limitations, this study advances an enriched view of change-induced collective voluntary turnover. Hopefully, findings here may encourage scholars to continue to explore the role that communicative tensions play in change-induced collective voluntary turnover in a variety of organizational settings. Hopefully, these lessons about communicative competence - learnt from the past - may help IT leaders improve the retention of talented IT employees. Retaining talented employees, the most strategic resource in IT, is crucial to the performance of the IS organization. Studies of change-induced collective voluntary turnover can provide IT leaders in this era of continual organizational change with new insights on how to better retain IT talent. 


\section{Acknowledgements}

I would like to thank the Senior Editor and two anonymous reviewers for their valuable guidance during the revision process. I am also grateful for the helpful comments I received on earlier versions of this manuscript from Richard Baskerville, Shiven Naidoo, and Cathy Urquhart.

\section{Appendix A}

Table A1: Key focus areas for IT employee turnover research since 2005

\begin{tabular}{|c|c|c|c|c|}
\hline Article & Topic & Theory & Paradigm & $\begin{array}{l}\text { Level of } \\
\text { Analysis }\end{array}$ \\
\hline Joseph et al. (2015) & $\begin{array}{l}\text { The relationships between relative pay } \\
\text { gap and patterns of job mobility }\end{array}$ & $\begin{array}{l}\text { Distributive justice, human capital } \\
\text { and stigmatization theories }\end{array}$ & Positivist & Single \\
\hline Maier et al. (2015) & $\begin{array}{l}\text { Techno-stressors and techno-exhaustion } \\
\text { as antecedents of turnover intention }\end{array}$ & $\begin{array}{l}\text { Work exhaustion model and Met } \\
\text { Expectation Theory }\end{array}$ & Positivist & Single \\
\hline $\begin{array}{l}\text { Eckhardt et al. } \\
\text { (2014) }\end{array}$ & $\begin{array}{l}\text { Personality of IT personnel and turnover } \\
\text { intention across IT job types }\end{array}$ & $\begin{array}{l}\text { Five-factor personality model and } \\
\text { the basic turnover model }\end{array}$ & Positivist & Single \\
\hline Maier et al. (2013) & $\begin{array}{l}\text { The impact of HRIS implementations on } \\
\text { HR personnel's job satisfaction and } \\
\text { turnover intention }\end{array}$ & $\begin{array}{l}\text { Technology Acceptance Model } \\
\text { (TAM) }\end{array}$ & Positivist & Single \\
\hline Chang et al. (2012) & $\begin{array}{l}\text { Career anchors and disturbances in job } \\
\text { turnover decisions }\end{array}$ & Discrepancy theory & Positivist & Single \\
\hline Joseph et al. (2012) & $\begin{array}{l}\text { Career histories, mobility patterns, and } \\
\text { career success of individuals }\end{array}$ & Career stage theory & Positivist & Single \\
\hline $\begin{array}{l}\text { Cho and Huang } \\
\text { (2012) }\end{array}$ & $\begin{array}{l}\text { Professional commitment, organizational } \\
\text { commitment, and the intention to leave } \\
\text { for professional advancement }\end{array}$ & $\begin{array}{l}\text { Organizational commitment and } \\
\text { cognitive dissonance theory }\end{array}$ & Positivist & Single \\
\hline Jiang (2011) & $\begin{array}{l}\text { A discrepancy model of IS personnel } \\
\text { turnover }\end{array}$ & $\begin{array}{l}\text { Organizational socialization } \\
\text { theory and } \\
\text { discrepancy theory }\end{array}$ & Positivist & Single \\
\hline $\begin{array}{l}\text { Ghapanchi and } \\
\text { Aurum (2011) }\end{array}$ & $\begin{array}{l}\text { A systematic literature review of the } \\
\text { antecedents to IT personnel's intentions } \\
\text { to leave }\end{array}$ & Not applicable & $\begin{array}{l}\text { Literature } \\
\text { review }\end{array}$ & $\begin{array}{l}\text { Not } \\
\text { applicable }\end{array}$ \\
\hline Calisir et al. (2011) & $\begin{array}{l}\text { Factors affecting intention to quit among } \\
\text { IT professionals in Turkey }\end{array}$ & $\begin{array}{l}\text { Organizational role theory and the } \\
\text { theory of planned behaviour }\end{array}$ & Positivist & Single \\
\hline $\begin{array}{l}\text { Zhao and Rashid } \\
\text { (2010) }\end{array}$ & $\begin{array}{l}\text { The mediating role of work-leisure } \\
\text { conflict on job stress and retention of it } \\
\text { professionals }\end{array}$ & $\begin{array}{l}\text { Role theory and work spill over } \\
\text { theory }\end{array}$ & Positivist & Single \\
\hline $\begin{array}{l}\text { Ragu-Nathan et al. } \\
\text { (2008) }\end{array}$ & $\begin{array}{l}\text { Technostress for End Users and } \\
\text { Continuance Commitment }\end{array}$ & $\begin{array}{l}\text { Transaction-Based } \\
\text { Model }\end{array}$ & Positivist & Single \\
\hline Lacity et al. (2008) & $\begin{array}{l}\text { Turnover intentions of Indian IS } \\
\text { professionals }\end{array}$ & $\begin{array}{l}\text { Met expectations theory and } \\
\text { social exchange theory }\end{array}$ & Positivist & Single \\
\hline Rutner et al. (2008) & $\begin{array}{l}\text { Emotional dissonance as a factor of IT } \\
\text { professionals work exhaustion, job } \\
\text { satisfaction, and turnover intention }\end{array}$ & $\begin{array}{l}\text { Work exhaustion model and } \\
\text { Emotional labour theory }\end{array}$ & Positivist & Single \\
\hline Joseph et al. (2007) & $\begin{array}{l}\text { A narrative literature review on turnover } \\
\text { of information technology professionals }\end{array}$ & Not applicable & $\begin{array}{l}\text { Literature } \\
\text { review }\end{array}$ & $\begin{array}{l}\text { Not } \\
\text { applicable }\end{array}$ \\
\hline Ahuja, et al. (2007) & The antecedents of turnover intention & Work exhaustion model & Positivist & Single \\
\hline
\end{tabular}




\begin{tabular}{|l|l|l|l|l|}
\hline & $\begin{array}{l}\text { among information technology road } \\
\text { warriors }\end{array}$ & & Positivist & Single \\
\hline $\begin{array}{l}\text { Paré and Tremblay } \\
(2007)\end{array}$ & $\begin{array}{l}\text { The influence of high-involvement } \\
\text { human resources practices on IT } \\
\text { Professionals' Turnover Intentions }\end{array}$ & Human capital theory & $\begin{array}{l}\text { Positivist } \\
\text { (causal } \\
\text { maps) }\end{array}$ & $\begin{array}{l}\text { Single } \\
\text { Females }\end{array}$ \\
\hline $\begin{array}{l}\text { Armstrong et al. } \\
(2007)\end{array}$ & $\begin{array}{l}\text { Advancement, voluntary turnover and } \\
\text { women in IT }\end{array}$ & Quality of work life theory & $\begin{array}{l}\text { Positivist } \\
\text { Employee } \\
\text { and } \\
\text { Managerial } \\
\text { Level }\end{array}$ \\
\hline $\begin{array}{l}\text { LeRouge et al. } \\
\text { (2006) }\end{array}$ & $\begin{array}{l}\text { The impact of role stress fit and self- } \\
\text { esteem on the job attitudes of IT } \\
\text { professionals }\end{array}$ & $\begin{array}{l}\text { Standpoint and communication } \\
\text { boundary management theory }\end{array}$ & &
\end{tabular}

Table A2: A summary of the opportunities for future IT turnover studies

\begin{tabular}{|c|c|}
\hline Area of Limitation & Description of opportunities for advancing theory \\
\hline Level of inquiry & $\begin{array}{l}\text { The majority of IT turnover research focuses on a single-level and the individual } \\
\text { employee. A multi-level analysis considers how individual, group, and } \\
\text { organizational units interact to influence employee voluntary turnover. }\end{array}$ \\
\hline Theoretical frameworks & $\begin{array}{l}\text { Models of IT voluntary employee turnover have drawn from a number of referent } \\
\text { organizational behaviour theories that emphasise individual-level explanations. } \\
\text { Scholars need to expand their conceptual lenses to group-level and other macro and } \\
\text { meso explanations to explain voluntary turnover behaviour. }\end{array}$ \\
\hline $\begin{array}{l}\text { Variance / Process } \\
\text { Models }\end{array}$ & $\begin{array}{l}\text { The majority of IS turnover research applies variance models at a specific point in } \\
\text { time to measure individual variations among IT employees that influence their } \\
\text { individual reactions. Process models based on longitudinal studies can be used } \\
\text { explain how a sequence of events unfolds over time to culminate into voluntary } \\
\text { employee turnover. }\end{array}$ \\
\hline Method of inquiry & $\begin{array}{l}\text { The majority of IT turnover research adopts survey based approaches. Surveys are } \\
\text { limited in incorporating relevant contextual features that explain employee actions. } \\
\text { Case studies can be used to study IT turnover as an emergent phenomenon over a } \\
\text { longer time span and at multiple levels. }\end{array}$ \\
\hline Turnover Intentions & $\begin{array}{l}\text { The majority of IT turnover research employs turnover intentions as the main } \\
\text { independent variable. However, not all turnover intentions manifests into actual } \\
\text { turnover, and some turnover can occur without explicit intentions. Therefore, } \\
\text { studying exogenous shocks and organizational change, and how these relate to } \\
\text { actual turnover can provide more valid models of turnover behaviour. }\end{array}$ \\
\hline Context & $\begin{array}{l}\text { Few IT turnover studies have done justice to the contextual richness of the turnover } \\
\text { process. Studies can provide insights that are relevant to a broader understanding of } \\
\text { turnover by turning its attention to specific multi-level contexts. }\end{array}$ \\
\hline Turnover decisions & $\begin{array}{l}\text { The majority of IS turnover research assumes that turnover is driven by individual } \\
\text { decisions. Turnover decisions, while ultimately personal, can sometime manifest } \\
\text { because of underlying group processes. }\end{array}$ \\
\hline
\end{tabular}


Table A3: Current multi-level collective employee turnover theories from the HR literature

\begin{tabular}{|c|c|c|c|c|}
\hline Theories & $\begin{array}{c}\text { Theoretical } \\
\text { lenses }\end{array}$ & $\begin{array}{c}\text { Key antecedent } \\
\text { categories/phases }\end{array}$ & Summary of theory & $\begin{array}{l}\text { Variance/ } \\
\text { Process }\end{array}$ \\
\hline $\begin{array}{l}\text { Context- } \\
\text { emergent } \\
\text { turnover (CET) } \\
\text { theory (Nyberg } \\
\text { et al., 2013) }\end{array}$ & $\begin{array}{l}\text { Climate and } \\
\text { environmental } \\
\text { complexity } \\
\text { and } \\
\text { resourced } \\
\text { based view } \\
\text { (RBV) }\end{array}$ & $\begin{array}{l}\text { Time, climate, } \\
\text { knowledge, skills, } \\
\text { abilities, and other } \\
\text { characteristics } \\
\text { (KSAOs), Human } \\
\text { capital }\end{array}$ & $\begin{array}{l}\text { Focuses on the consequences of } \\
\text { collective turnover. } \\
\text { Views collective turnover as } \\
\text { the quantity and quality of } \\
\text { depletion (KSAOs) from an } \\
\text { organizational unit. }\end{array}$ & $\begin{array}{l}\text { Variance } \\
\text { and Process }\end{array}$ \\
\hline $\begin{array}{l}\text { Collective } \\
\text { affective } \\
\text { commitment } \\
\text { model (Gardner } \\
\text { and Wright, } \\
\text { 2011) }\end{array}$ & $\begin{array}{l}\text { Group } \\
\text { emotional } \\
\text { contagion and } \\
\text { collective } \\
\text { commitment } \\
\text { theories }\end{array}$ & $\begin{array}{l}\text { Collective affective } \\
\text { commitment, HR } \\
\text { practices, } \\
\text { unemployment rate, } \\
\text { union status }\end{array}$ & $\begin{array}{l}\text { Focuses on the influence of } \\
\text { motivation, HR practices, and } \\
\text { collective commitment on } \\
\text { collective turnover. }\end{array}$ & Variance \\
\hline $\begin{array}{l}\text { Turnover } \\
\text { Contagion } \\
\text { Model } \\
\text { (Felps et al., } \\
\text { 2009) }\end{array}$ & $\begin{array}{l}\text { Social } \\
\text { comparison } \\
\text { theory }\end{array}$ & $\begin{array}{l}\text { Individual job } \\
\text { embeddedness and } \\
\text { co-workers' job } \\
\text { embeddedness }\end{array}$ & $\begin{array}{l}\text { Examines the extent to which } \\
\text { co-workers' job embeddedness } \\
\text { and job search behaviours } \\
\text { explains why people leave their } \\
\text { jobs. }\end{array}$ & Variance \\
\hline $\begin{array}{l}\text { Process model } \\
\text { of collective } \\
\text { turnover } \\
\text { (Bartunek et al., } \\
\text { 2008) }\end{array}$ & $\begin{array}{l}\text { Largely } \\
\text { grounded } \\
\text { theory and } \\
\text { voice } \\
\text { behaviour } \\
\text { theory }\end{array}$ & $\begin{array}{l}\text { Dissatisfaction and } \\
\text { complaints, group } \\
\text { processes, relational } \\
\text { context, exit } \\
\text { behaviour, boundary } \\
\text { conditions }\end{array}$ & $\begin{array}{l}\text { Employees with negative } \\
\text { experience choose to leave their } \\
\text { organization in close temporal } \\
\text { proximity, if the concerns they } \\
\text { have voiced are not addressed. } \\
\text { This is based on shared social } \\
\text { processes through group } \\
\text { sensemaking and emotional } \\
\text { contagion. }\end{array}$ & Process \\
\hline $\begin{array}{l}\text { Communicative } \\
\text {-tension model } \\
\text { of change- } \\
\text { induced } \\
\text { collective } \\
\text { voluntary } \\
\text { turnover } \\
\text { (Present study) }\end{array}$ & $\begin{array}{l}\text { Relational } \\
\text { dialectics } \\
\text { theory }\end{array}$ & $\begin{array}{l}\text { Communicative } \\
\text { tensions, turning } \\
\text { points, } \\
\text { communicative } \\
\text { practices, boundary } \\
\text { conditions }\end{array}$ & $\begin{array}{l}\text { Collective turnover unfolds } \\
\text { when some employees become } \\
\text { collectively dissatisfied about } \\
\text { the negative communicative } \\
\text { practices that managers use to } \\
\text { manage communicative } \\
\text { tensions during an } \\
\text { organizational change and other } \\
\text { placements are available in the } \\
\text { market. }\end{array}$ & Process \\
\hline
\end{tabular}




\section{References}

Ahuja, M. K., Chudoba, K. M., Kacmar, C. J., Mcknight, D. H., George, J. F., 2007. IT Road Warriors: Balancing Work-Family Conflict, Job Autonomy, and Work Overload to Mitigate Turnover Intentions. MIS Quarterly 31 (1), 1-17.

Allen, M. W., Armstrong, D. J., Riemenschneider, C. K., Reid, M. F., 2006. Making sense of the barriers women face in the information technology work force: Standpoint theory, Self-disclosure, and causal maps. Sex Roles 54 (11-12), 831-844.

Altman, I., 1993. Dialectics, physical environments, and personal relationships. Communication Monographs 60 (1), 26-34.

Armstrong, D. J., Brooks, N. G., Riemenschneider, C. K., 2015. Exhaustion from information system career experience: implications for turn-away intention. MIS Quarterly 39 (3), 713-727.

Armstrong, D. J., Riemenschneider, C. K., Allen, M. W., Reid, M. F., 2007. Advancement, voluntary turnover and women in IT: A cognitive study of work-family conflict. Information and Management 44 (2), 142-153.

Baker, B., 1995. The role of feedback in assessing information systems planning effectiveness. Journal of Strategic Information Systems 4 (1), 61-80.

Baron, J.N., Hannan, M.T., Burton, M.D., 2001. Labor Pains: Change in Organizational Models and Employee Turnover in Young, High-Tech Firms. American Journal of Sociology 106 (4), 9601012.

Barsade, S., 2002. The ripple effect: Emotional contagion and its influence on group behaviour. Administrative Science Quarterly 47 (4), 644-675.

Bartunek, J. M., Huang, Z., Walsh, I. J., 2008. The development of a process model of collective turnover. Human Relations 61 (5), 5-37.

Baxter, L. A., 2011. Voicing relationships: A dialogic perspective. Sage, California.

Baxter, L. A., Braithwaite, D. O., 2009. Relational dialectics theory, applied. In: Smith, S. W. S. (Ed.), New directions in interpersonal communication (pp. 48-66). Sage, Los Angeles.

Baxter, L. A., Braithwaite, D. O., Nicholson, J. H., 1999. Turning points in the development of blended families. Journal of Social and Personal Relationships 16 (3), 291-314.

Baxter, L. A., Montgomery, B. M., 1996. Relating: Dialogues and dialectics. Guilford Press, New York.

Baxter, L. A., Pittman, G., 2001. Communicatively remembering turning points of relational development in heterosexual romantic relationships. Communication Reports 14 (1), 1-17.

Benson, J. K., 1977. Organizations: A Dialectical View. Administrative Science Quarterly 22 (1), 121.

Bharadwaj, A., El Sawy, O., Pavlou, P., Venkatraman, N., 2013. Digital business strategy: toward a next generation of insights. MIS Quarterly 37 (2), 471-482. 
Berger, P., 1967. The Social Reality of Religion. Chaucer Press, Suffolk.

Berger, P. L., Luckmann, T., 1967. The Social Construction of Reality: A Treatise in the Sociology of Knowledge. Anchor Books, New York.

Burnes, P. T., 2006. Voluntary employee turnover: Why IT professionals leave. IT Professional 8 (3), 46-48.

Calisir, F., Gumussoy, C. A., Iskin, I., 2011. Factors affecting intention to quit among IT professionals. Personnel Review 40 (4), 514-533.

Chang, C. L. H., Jiang, J. J., Klein, G., Chen, H. G., 2012. Career anchors and disturbances in job turnover decisions - A case study of IT professionals in Taiwan. Information and Management 49 (6), 309-319.

Cho, S., Mathiassen, L., Robey, D., 2007. Dialectics of resilience: A multi-level analysis of a telehealth innovation. Journal of Information Technology 22 (1), 24-35.

Cho, V., Huang, X., 2012. Professional commitment, organizational commitment, and the intention to leave for professional advancement: An empirical study on IT professionals. Information Technology \& People 25 (1), 31-54.

Cinni, K. R., 2014. Job Satisfaction in Information Technology Industry: A Study in Kerala. Journal of Commerce \& Management Thought 5 (1), 76-90.

de Rond, M., Bouchikhi, H., 2004. On the Dialectics of Strategic Alliances. Organization Science 15 (1), 56-69.

Deetz, S., 1996. Crossroads-describing differences in approaches to organization science: Rethinking Burrell and Morgan and their legacy. Organization science 7 (2), 191-207.

Dhanesh, G. S., 2015. Corporate social responsibility (CSR) in India: A dialectical analysis of the communicative construction of the meanings and boundaries of CSR in India. Public Relations Inquiry 4 (3), 287-303.

Dinger, M., Thatcher, J. B., Stepina, L. P., Craig, K., 2012. The grass is always greener on the other side: A test of present and alternative job utility on IT professionals' turnover.

IEEE Transactions on Engineering Management 59 (3), 364-378.

Dumlao, R. J., Janke, E. M., 2012. Using Relational Dialectics to Address Differences in CommunityCampus Partnerships. Journal of Higher Education Outreach and Engagement 16 (2), 151-176.

Earl, M., 1993. Experiences in strategic information systems planning. MIS Quarterly 17 (1), 1-21.

Eckhardt, A., Laumer, S., Maier, C., Weitzel, T., 2014. The effect of personality on IT personnel's job-related attitudes: establishing a dispositional model of turnover intention across IT job types. Journal of Information Technology 31 (1), 48-66.

Erbert, L. A., Mearns, G. M., Dena, S., 2005. Perceptions of Turning Points and Dialectical Interpretations in Organizational Team Development. Small Group Research 36 (1), 21-58.

Erturk, A., 2014. Influences of HR Practices, Social Exchange, and Trust on Turnover Intentions of Public IT Professionals. Public Personnel Management 43 (1), 140-175. 
Felps, W., Mitchell, T. R., Hekman, D. R., Lee, T. W., Holtom, B. C., Harman, W. S., 2009. Turnover contagion: how coworkers' job embeddedness and job search behaviors influence quitting. Academy of Management Journal 52 (3), 545-561.

Ford, J. D., Ford, L. W., 1994. Logics of identity, contradiction, and attraction in change. Academy of Management Review 19 (4), 756-785.

Ford, J. D., Ford, L. W., 1995. The Role of Conversations in Producing Intentional Change in Organizations. Academy of Management Review 20 (3), 541-570.

Ford, J. D., Ford, L. W., 2008. Conversational Profiles: A Tool for Altering the Conversational Patterns of Change Managers. The Journal of Applied Behavioral Science 44 (4), 445-467.

Ford, J. D., Ford, L. W., McNamara, R. T., 2002. Resistance and the background conversations of change. Journal of Organizational Change Management 15 (2), 105-121.

Galliers, R. D., 1991. Strategic information systems planning: myths, reality and guidelines for successful implementation. European Journal of Information Systems 1 (1), 55-64.

Galliers, R.D., 1993. IT strategies: beyond competitive advantage. Journal of Strategic Information Systems 2 (4), 283-291.

Galliers, R. D., Land, F. F., 1987. Viewpoint: choosing appropriate information systems research methodologies. Communications of the ACM 30 (11), 901-902.

Galliers, R.D., Newell, S., 2003. Back to the future: from knowledge management to the management of information and data. Information Systems and e-Business Management 1 (1), 5-13.

Gardner, T. M., Wright, P. M., 2011. The impact of motivation, empowerment, and skill-enhancing practices on aggregate voluntary turnover: the mediating effect of collective affective commitment. Personnel Psychology 64, 315-350.

Garvey, A., Silva, M., 2010. Development of communication, self and emotions in childhood: contributions from the relational and dialogical perspectives. Educar Em Revista 1 (36), 55-64.

Ghapanchi, A. H., Aurum, A., 2011. Antecedents to IT personnel's intentions to leave: A systematic literature review. Journal of Systems and Software 84 (2), 238-249.

Gibbs, J., 2009. Dialectics in a global software team: Negotiating tensions across time, space, and culture. Human Relations 62 (6), 905-935.

Giddens, A., 1984. The Constitution of Society: Outline of the Theory of Structuration. Polity Press, Cambridge.

Goswami, S., 2014. Work-Life Conflict Among IT Professionals. The IUP Journal of Organizational Behavior XIII (4), 38-59.

Hall, T., Beecham, S., Verner, J., Wilson, D., 2008. The Impact of Staff Turnover on Software Projects: The Importance of Understanding What Makes Software Practitioners Tick. In: Sigmis-CPR '08: Proceedings of the 2008 ACM SIGMIS CPR Conference on Computer Personnel Research, Charlottesville, Virginia, USA, pp. 30-39. 
Hardy, C., Lawrence, T. B., Grant, D., 2005. Discourse and collaboration: The role of conversations and collective identity. Academy of Management Review 30 (1), 58-77.

Hausknecht, J. P., Trevor, C. O., 2011. Collective Turnover at the Group, Unit, and Organizational Levels: Evidence, Issues, and Implications. Journal of Management 37 (1), 352-388.

Heavey, A. L., Holwerda, J. A, Hausknecht, J. P., 2013. Causes and consequences of collective turnover: A meta-analytic review. Journal of Applied Psychology 98 (3), 412-453.

Henderson, J., Venkatraman, N., 1993. Strategic alignment: leveraging information technology for transforming organizations. IBM Systems Journal 32 (1), 4-16.

Holquist, M., 2002. Dialogism (2nd ed.). Routledge, New York.

Holtom, B. C., Mitchell, T. R., Lee, T. W., Eberly, M. B., 2008. Turnover and Retention Research: A Glance at the Past, a Closer Review of the Present, and a Venture into the Future. The Academy of Management Annals 2 (1), 231-274.

Holtom, B. C., Mitchell, T. R., Lee, T. W., Inderrieden, E. J., 2005. Shocks as causes of turnover: What they are and how organizations can manage them. Human Resource Management 44 (3), 337-352.

Jay, J., 2013. Navigating paradox as a mechanism of change and innovation in hybrid organizations. Academy of Management Journal 56 (1), 137-159.

Jian, G., 2007. "Omega is a Four-Letter Word": Toward a Tension-Centered Model of Resistance to Information and Communication Technologies. Communication Monographs 74 (4), 517-540.

Jiang, J. J., 2011. A Discrepancy Model of Information System Personnel Turnover. Journal of Management 19 (2), 249-272.

Joseph, D., Ang, S., Slaughter, S. A., 2015. Turnover or Turnaway? Competing Risks Analysis of Male and Female IT Professionals' Job Mobility and Relative Pay Gap. Information Systems Research 26 (1), 145-164.

Joseph, D., Boh, W. F., Ang, S., Slaughter, S. A., 2012. The career paths less (or more) travelled: a sequence analysis of it career histories, mobility patterns, and career success. MIS Quarterly $36(2), 427-452$.

Joseph, D., Ng, K., Koh, C., Ang, S., 2007. Turnover of Information Technology Professionals: A Narrative Review, Meta-Analytic Structural Equation Modelling, and Model Development. MIS Quarterly 31 (3), 547-577.

Kovoor-Misra, S., 2009. Understanding perceived organizational identity during crisis and change: A threat/opportunity framework. Journal of Organizational Change Management 22 (5), 494-510.

Kyriakidou, O., 2011. Relational perspectives on the construction of meaning: A network model of change interpretation. Journal of Organizational Change Management 24 (5), 572-592.

Lacity, M. C., Hirschheim, R., 1993. The information systems outsourcing bandwagon. Sloan management review 35 (1), 73-87. 
Lacity, M. C., Iyer, V. V., Rudramuniyaiah, P. S., 2008. Turnover intentions of Indian IS professionals. Information Systems Frontiers 10 (2), 225-241.

Langley, A., Montréal, H. E. C., 2007. Process Thinking in Strategic Organization. Strategic Organization 5 (3), 271-282.

Laumer, S., Maier, C., Eckhardt, A., Weitzel, T., 2014. Why are they grumbling about my new system? Theoretical foundation and empirical evidence of employee grumbling as a user resistance behavior. In: ICIS '35: Proceeedings of the Thirty Fifth International Conference on Information Systems, Auckland, pp. 1-19.

Lee, A. S., Baskerville, R. L., 2003. Generalizing Generalizability in Information Systems Research. Information Systems Research 14 (3), 221-243.

Lee, Y.J., Roth, W.M., 2007. The individual|collective dialectic in the learning organization. The Learning Organization 14 (2), 92-107.

LeRouge, C., Nelson, A., Blanton, J. E., 2006. The impact of role stress fit and self-esteem on the job attitudes of IT professionals. Information and Management 43 (8), 928-938.

Maier, C., Laumer, S., Eckhardt, A., 2015. Information Technology as Daily Stressor: Pinning Down the Causes of Burnout. Journal of Business Economics 85 (4), 349-387.

Maier, C., Laumer, S., Eckhardt, A., Weitzel, T., 2013. Analyzing the impact of HRIS implementations on HR personnel's job satisfaction and turnover intention. Journal of Strategic Information Systems 22 (3), 193-207.

Marabelli, M., Galliers, R. D., 2016. A reflection on information systems strategizing: the role of power and everyday practices. Information Systems Journal doi:10.1111/isj.12110. forthcoming.

Mason, R. O., 1969. A Dialectical Approach to Strategic Planning. Management Science 15 (8), $403-$ 414.

Mason, R. O., Mckenney, J. L., Copeland, D. G., 1997. Steps Why Use an Historical Method? MIS Quarterly 21 (3), 307-320.

Mcgrath, K., 2007. Power, Rationality and the Art of Living Power Through Socio-Technical Change. MIS Quarterly 31 (2), 295-315.

Murphy, R., 1971. Dialectics of social life. Basic Books, New York.

Myers, M. D., Klein, H., 1999. A set of principles for conducting and evaluating interpretive field studies in information systems. MIS Quarterly 23 (1), 67-93.

Nayar, V., 2010. Employees first, customers second: Turning conventional management upside down. Harvard Business Press, Massachusetts.

Nyberg, A. J., Ployhart, R. E., Carolina, S., 2013. Context-emergent turnover theory: a theory of collective turnover. Academy of Management Review 38 (1), 109-131.

Orlikowski, W. J., Baroudi, J. J., 1991. Studying information technology in organizations: Research approaches and assumptions. Information systems research 2 (1), 1-28. 
Rutner, P.S., Hardgrave, B.C., McKnight, D. H., 2008. Emotional Dissonance and the Information Technology Professional. MIS Quarterly 32 (3), 635-652.

Paré, G., Tremblay, M., 2007. The Influence of on Information Technology Professionals ' Turnover Intentions. Group \& Organization Management 32 (3), 326-357.

Pettigrew, A. M., Woodman, R. W., Cameron, K. S., 2001. Studying organizational change and development: for future research. The Academy of Management Journal 44 (4), 697-713.

Peppard, J., Galliers, R. D., Thorogood, A., 2014. Information systems strategy as practice:

Micro strategy and strategizing for IS. Journal of Strategic Information Systems 23 (1), 1-10.

Peppard, J., Ward, J., 2004. Beyond strategic information systems: towards an IS capability. Journal of Strategic Information Systems 13 (2), 167-194.

Porra, J., Hirschheim, R., Parks, M. S., 2014. The Historical Research Method and Information Systems Research. Journal of the Association for Information Systems 15 (9), 536-576.

Putnam, L. L., 2004. Dialectical Tensions and Rhetorical Tropes in Negotiations. Organization Studies 25 (1), 35-53.

Rafferty, A. E., Griffin, M. A., 2006. Perceptions of organizational change: a stress and coping perspective. The Journal of Applied Psychology 91 (5), 1154-1162.

Ready, D. A., Hill, L. A., Conger, J. A., 2008. Winning the race for talent in emerging markets. Harvard Business Review 86 (11), 62-70.

Reich, B., Benbasat, I., 2000. Factors that influence the social dimension of alignment between business and information technology objectives. MIS Quarterly 24 (1), 81-113.

Ragu-Nathan, T. S., Tarafdar, M., Ragu-Nathan, B. S., Tu, Q., 2008. Consequences of Technostress for End Users in Organizations: Conceptual Development and Empirical Validation. Information Systems Research 19 (4), 417-433.

Rawlins, W. K., 1992. Friendship matters: Communication, dialectics, and the life course. de Gruyter, New York.

Rivard, S., Raymond, L., Verreault, D., 2006. Resource-based view and competitive strategy: an integrated model of the contribution of information technology to firm performance. Journal of Strategic Information Systems 15 (1), 29-50.

Robey, D., Holmstrom, J., 2001. Transforming municipal governance in global context: A case study of the dialectics of social change. Journal of Global Information Technology Management 4 (4), 19-31.

Ross, J., Beath, C., Goodhue, D., 1996. Develop long-term competitiveness through IT assets. Sloan Management Review 38 (1), 31-42.

Sabherwal, R., Newman, M., 2003. Persistence and change in system development: A dialectical view. Journal of Information Technology 18 (2), 69-92. 
Sambamurthy, V., Bharadwaj, A., Grover, V., 2003. Shaping agility through digital options: reconceptualizing the role of information technology in contemporary firms. MIS Quarterly 27 (2), 237-263.

Schore, A.N., 2000. Attachment and the regulation of the right brain. Attachment \& Human Development 2 (1), 23-47.

Schweiger, D. M., Denisi, A. S., 1991. Communication with Employees Following a Merger: a Longitudinal Field Experiment. Academy of Management Journal 34 (1), 110-135.

Scott, C. R., Connaughton, S. L., Diaz-Saenz, H. R., Maguire, K., Ramirez, R., Richardson, B., Morgan, D., 1999. The Impacts of Communication and Multiple Identifications on Intent to Leave: A Multimethodological Exploration. Management Communication Quarterly 12 (3), 400-435.

Seo, M.G., Putnam, L. L., Bartunek, J., 2004. Dualities and tensions of planned organizational change. In: Poole, M.S., van de Ven A.H., (Ed.), Handbook of organizational change and innovation (pp. 73-107). Oxford University Press, New York.

Steffens, N. K., Haslam, S. A., Reicher, S. D., Platow, M. J., Fransen, K., Yang, J., Boen, F., 2014. Leadership as social identity management: Introducing the Identity Leadership Inventory (ILI) to assess and validate a four-dimensional model. Leadership Quarterly 25 (5), 10011024 .

Strauss, A. L., Corbin, J. M., 1998. Basics of qualitative research (2nd ed.). Sage, Thousand Oaks.

Tornack, C., Schumann, M., 2014. How to Avoid Empty Chairs in IT Divisions? IS Supported Succession Management to Control Development and Retention of IT Professionals. In: ACIS '20: Twentieth Americas Conference on Information Systems, Savannah, pp. 1-10.

Tracy, S. J., 2004. Dialectic, contradiction, or double bind? Analysing and theorizing employee reactions to organizational tension. Journal of Applied Communication Research 32 (2), 119146.

van de Ven, A. H., 2007. Engaged scholarship: a guide for organizational and social research: a guide for organizational and social research. Oxford University Press, Oxford.

van de Ven, A. H., Huber, G. P., 1990. Longitudinal Field Research Methods for Studying Processes of Organizational Change. Organization Science 1 (3), 213-219.

van de Ven, A. H., Poole, M. S., 1995. Explaining development and change. The Academy of Management Review 20 (3), 510-540.

van Knippenberg, B., Martin, L., Tyler, T., 2006. Process-orientation versus outcome-orientation during organizational change: The role of organizational identification. Journal of Organizational Behavior 27 (6), 685-704.

Walsham, G., 1995. Interpretive case studies in IS research: nature and method. European Journal of Information Systems 4 (2), 74-81.

Walsham, G., Waema, T., 1994. Information systems strategy and implementation: A case study of a Building Society. ACM Transactions on Information Systems 12 (2), 150-173. 
Wasko, M. M., Faraj, S., 2005. Why should I share? Examining social capital and knowledge contribution in electronic networks of practice. MIS Quarterly 29 (1), 35-57.

Zhao, L., Rashid, H., 2010. The Mediating Role of Work-Leisure Conflict on Job Stress and Retention of IT. Academy of Information and Management Sciences Journal 13 (2), 25-41. 